2016

\title{
The Effects of Self-Stigma on Occupational Engagement for Adults with Mental IIIness
}

Alyssa A. Kostreba

University of North Dakota

Taylor E. LaVoi

University of North Dakota

How does access to this work benefit you? Let us know!

Follow this and additional works at: https://commons.und.edu/ot-grad

Part of the Occupational Therapy Commons

\section{Recommended Citation}

Kostreba, Alyssa A. and LaVoi, Taylor E., "The Effects of Self-Stigma on Occupational Engagement for Adults with Mental Illness" (2016). Occupational Therapy Capstones. 111.

https://commons.und.edu/ot-grad/111

This Scholarly Project is brought to you for free and open access by the Department of Occupational Therapy at UND Scholarly Commons. It has been accepted for inclusion in Occupational Therapy Capstones by an authorized administrator of UND Scholarly Commons. For more information, please contact und.commons@library.und.edu. 
THE EFFECTS OF SELF-STIGMA ON OCCUPATIONAL ENGAGEMENT FOR ADULTS WITH MENTAL ILLNESS

\author{
by \\ Alyssa A. Kostreba, MOTS \\ and \\ Taylor E. LaVoi, MOTS \\ Advisor: Sonia Zimmerman, Ph.D., OTR/L, FAOTA
}

An Independent Study

Submitted to the Occupational Therapy Department

of the

University of North Dakota

In partial fulfillment of the requirements

for the degree of

Master of Occupational Therapy

\author{
Grand Forks, North Dakota \\ May \\ 2016
}




\section{APPROVAL PAGE}

This Independent Study, submitted by Alyssa A. Kostreba and Taylor E. LaVoi in partial fulfillment of the requirement for the Degree of Master of Occupational Therapy from the University of North Dakota, has been read by the Faculty Advisor under whom the work has been done and is hereby approved.
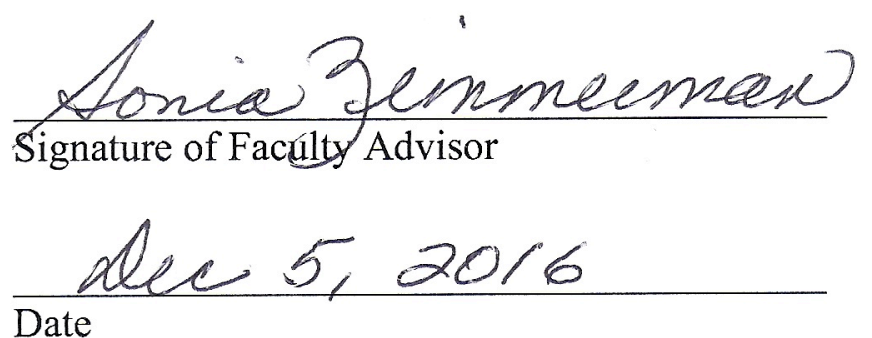


\section{PERMISSION}

Title: $\quad$ The effects of self-stigma on occupational participation for adults with mental illness

Department: Occupational Therapy

Degree: $\quad$ Master of Occupational Therapy

In presenting this Independent Study in partial fulfillment of the requirements for a graduate degree from the University of North Dakota, we agree that the Department of Occupational Therapy shall make it freely available for inspection. We further agree that permission for extensive copying for scholarly purposes may be granted by the professor who understood that any copying or publication or other use of this Independent Study or part thereof for financial gain shall not be allowed without our written permission. It is also understood that due recognition shall be given to us and the University of North Dakota in any scholarly use which may be made of any material in our Independent Study Report.

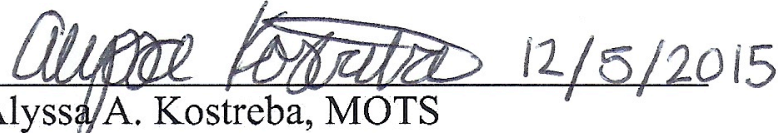

Alyssa A. Kostreba, MOTS

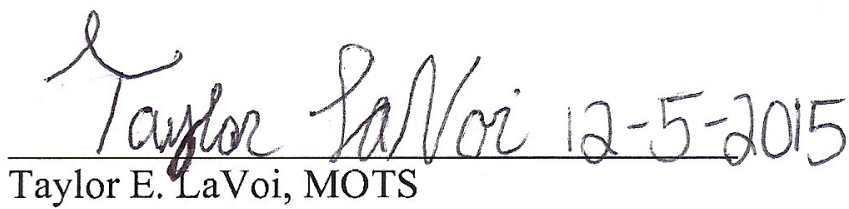




\section{TABLE OF CONTENTS}

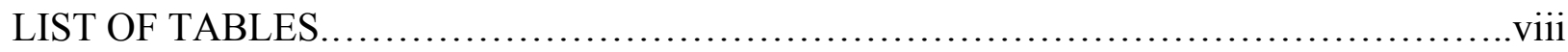

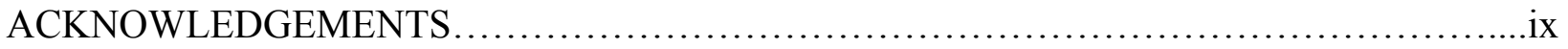

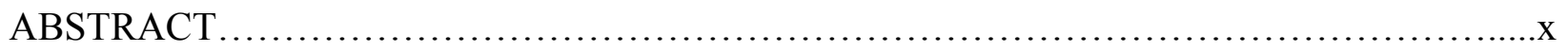

CHAPTER

I. THE PROBLEM...............................................................

Rationale ..........................................................

Theoretical Framework................................................

Statement of the Problem.............................................

Assumptions............................................................

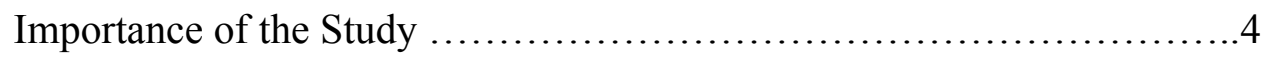

Scope and Delimitation.............................................. 4

Operational Definitions.............................................

Organization of Remaining Chapters....................................5

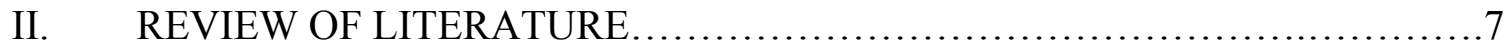

Introduction......................................................

Public-Stigma....................................................

Effects of Public Stigma on Families............................10

Effects of Public Stigma on Sense of Self......................10

Theoretical Models of Public Stigma...........................11

Assessments for Public Stigma................................12 
Interventions for Public Stigma..........................12

Self-Stigma................................................14

Prevalence of Self Stigma ...............................14

Effects of Self Stigma on the Individual....................... 15

Measuring Self Stigma...................................... 17

Interventions for Self Stigma.............................19

Self Stigma in Occupational Therapy Literature ................20

Problem Statement.............................................20

III. RESEARCH METHODOLOGY ......................................21

Research Purpose............................................21

Qualitative Research Design...................................21

Role of the Researcher.......................................22

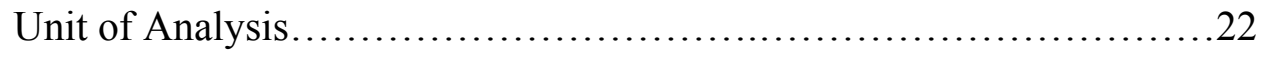

Sources of Data.............................................22

Locale of the Study..........................................22

Population and Sampling.......................................23

Instrumentation and Data Collection..............................23

Trustworthiness..................................................23

Tools for Data Analysis.........................................25

IV. PRESENTATION, ANALYSIS \& INTERPRETATION OF DATA ...............27

Analysis of Data.............................................. 27

Themes....................................................... 31

Negative Impact on Self..................................31 
Positive Contributions to One's Sense of Self.......................33

Acceptance of Diagnosis \& Acknowledged Need...................34

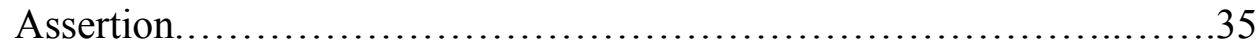

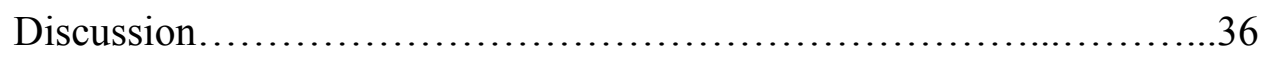

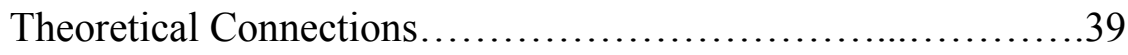

V. SUMMARY, CONCLUSIONS \& RECOMMENDATIONS.........................41

Summary of Findings................................................. 41

Conclusions........................................................... 41

Limitations and Recommendations......................................42

Implications....................................................... 42

Occupational Therapy .........................................42

Future Research..........................................43

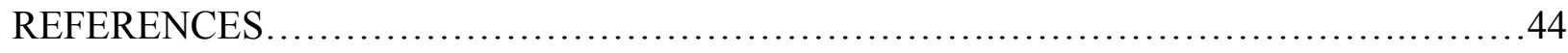

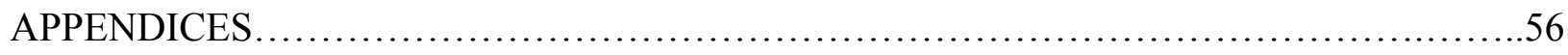

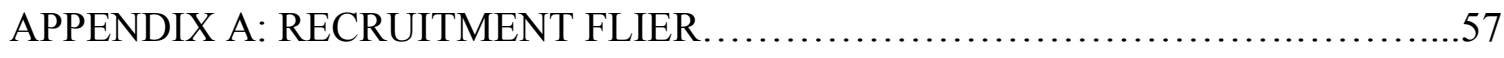

APPENDIX B: PRAIRIE HARVEST MENTAL HEALTH CONSENT ...................58

APPENDIX C: RESEARCHERS' CONFIDENTIALITY AGREEMENT..............59

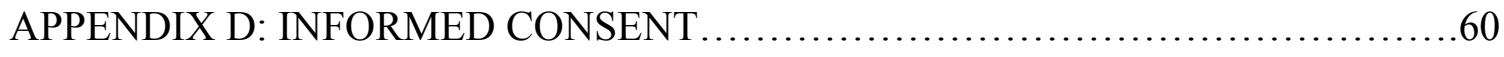

APPENDIX E: IRB APPROVAL ...............................................61

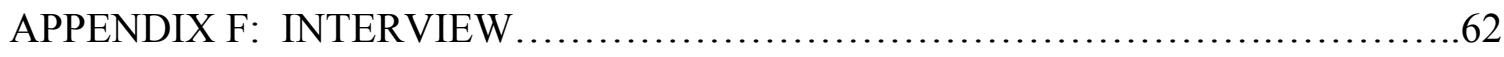

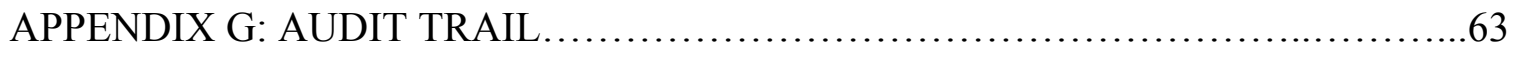

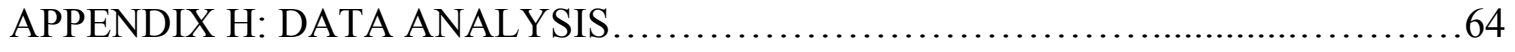


APPENDIX I: VERIFICATION OF MEMBER CHECKING $\ldots \ldots \ldots \ldots \ldots \ldots \ldots \ldots \ldots \ldots . \ldots 6$ 


\section{LIST OF TABLES}

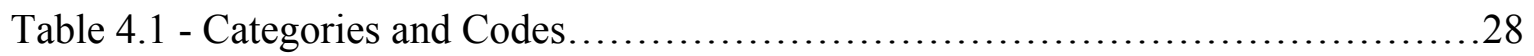

Table 4.1 - Themes and Textural/Structural Descriptions...........................30 


\section{ACKNOWLEDGMENTS}

The authors wish to thank the participants for their time and honesty. We would also like to thank our advisor, Dr. Sonia Zimmerman for her guidance and support during the course of our study. Lastly, we would like to thank our loved ones, especially Tebow and Rosie, for their companionship throughout our academic endeavors. 


\begin{abstract}
Purpose: The purpose of this study is to explore the impacts of self-stigma on everyday occupations of persons with serious and persistent mental illness. Greater understanding of the impacts of self-stigma is important to development of occupation-based interventions used by occupational therapists in mental health settings.

Methodology: A qualitative phenomenological approach was utilized to interview six participants between the ages of 31-58 years old with severe and persistent mental illness. High level in vivo coding was used to interpret participant responses.

Results: Four themes emerged from participant interviews: 1) negative impact on self, 2) coping with negative social encounters, 3) positive contributions to one's sense of self, and 4) acceptance of diagnosis and acknowledged need for medication. Self-stigma is experienced as changes in sense of self with the greatest impact shortly after the initial diagnosis of the mental illness; with time and external supports, the individual learns to accept and cope with the diagnosis, resulting in decreased self-stigma and increased occupational engagement.

Conclusion: Based on the results of the study, OTs are encouraged to provide interventions early in the course of the illness to counteract the negative impacts of self-esteem and self-efficacy associated with self-stigma on occupational engagement. Research findings could be used to develop a screening tool to determine the presence of self-stigma of clients receiving mental health OT services and guide intervention planning.
\end{abstract}




\section{CHAPTER 1}

\section{THE PROBLEM}

\section{Rationale}

Currently 61.5 million Americans have a mental illness (MI), and approximately 13.6 million have a severe MI such as schizophrenia, bipolar, or depression. The prevalence of these diagnosis cost the American government \$193.2 billion in healthcare costs (National Alliance Mental Illness [NAMI], 2013). Interestingly, mood disorders rank as the third most common cause of hospitalization for adults ages 18-44. According to World Health Organization [WHO] (2001), 450 million people have a mental health diagnosis; while two-thirds of those individuals do not seek health-care services. A common barrier by individuals with MI seeking health-care services is stigma. Stigma is depicted in three forms of societal influences: structural, public and self-stigma (Corrigan, Markowitz, \& Watson, 2004).

Structural stigma is described as the invisible forces within institutions and policies that limit equality of opportunities for individuals with MI (Corrigan et al., 2004). Public stigma refers to groups of persons possessing stereotypical and prejudiced beliefs towards individuals with a MI which commonly results in discriminatory action (Corrigan, Kerr, \& Knudsen, 2005). Lastly, self-stigma is defined as the internalized stereotypical and prejudiced beliefs held by individuals that influence self-esteem and self-efficacy (Livingston \& Boyd, 2010). Persons with MI experience diminished self-esteem and self-efficacy resulting in maladaptive coping mechanisms, altered life goals, and vacillating perceptions of identity. Other disciplines such as psychology, nursing, and social work have found that the internalization of stigma may cause the individual to experience detrimental effects on self-esteem and self-efficacy (Link \& Phelan, 
2001; Corrigan \& Watson, 2002; Corrigan, Watson, \& Barr, 2006; Yanos et al., 2008; Corrigan et al., 2009; Rusch et al., 2010).

Despite the documented varying reactions that may occur within persons with MI, the most prevalent response to self-stigma leaves individuals feeling susceptible to feelings of being devalued and discredited members of society (Livingston \& Boyd, 2010). In addition to diminished self-esteem and self-efficacy, feelings of isolation and alienation of individuals with MI are likely to occur as a result of self-stigma (Ritsher \& Phelan, 2004; Garin, Molero, \& Bos, 2015). Lower morale, lower satisfaction, and lower overall meaning and quality of life have additionally been noted to occur within individuals who experience self-stigma (Ritsher \& Phelan, 2004; Switaj, 2014; Ehrlich-Ben et al., 2013; Rusch et al., 2010).

\section{Theoretical Framework}

The ecology of human performance (EHP) theoretical framework was utilized to guide this qualitative study. EHP is an interdisciplinary approach envisioning the transactive encounters between a person and the context tasks within performance range are completed (Dunn, Brown, \& McGuigan, 1994). The person is comprised of personal variables which guide the occurrence of tasks in various contexts; these variables consist of values, interests, and experiences, as well as sensorimotor, cognitive, and psychosocial skills (Dunn et al., 1994). Contexts in which tasks occur include: social, cultural, physical, and temporal environments (Dunn et al., 1994). Performance range is the ability to utilize one's skills within various contexts to complete tasks. A task is a component of a goal completed in contexts (Dunn et al., 1994). Persons utilize their skills and capabilities in their performance range to complete tasks in various contexts. 
EHP aligns with this study in regards to the emphasis of one's performance range in the social and cultural contexts. Dunn et al. (1994) described how the EHP theoretical model presents an opportunity to view task performance for persons with MI through the lens of the environment in which tasks are being completed. EHP provides a framework to understand a person's [hindered or facilitated] performance range while completing tasks embedded in social and cultural contexts (Dunn et al., 1994). Furthermore, the model provides a foundation to evaluate the effects of internalized stigma associated with prejudice, discrimination, and stereotypes, on one's occupational engagement. The interdisciplinary intentions of the model serve to facilitate understanding across varying disciplines in regards to the effects of self-stigma on occupational engagement for adults with MI.

\section{Statement of the Problem}

In professions such as psychology and nursing, self-stigma has been found to negatively impact the quality of life (QoL) of persons with MI. However, to the researchers' knowledge, evidence in the profession of occupational therapy regarding the effects of self-stigma on occupational engagement of adults with MI, has not been pursued. The negative effects on selfesteem and self-efficacy identified in other professions and the OT literature associated with selfstigma leads to the purpose of the current study.

\section{Assumption}

Assumptions presumed based on current literature indicate that self-stigma poses as a barrier to occupational engagement for adults with MI. The purpose of the study is to determine the effects of self-stigma on persons with MI occupational engagement. It is anticipated that selfstigma will be reported to negatively influence aspects of their life in regards to social, work, and education goals. 


\section{Importance of the Study}

The study will provide results in regards to the effects of self-stigma on occupational engagement and QoL for persons with MI. The results of the study are expected to inform OT practitioners of the necessity to provide interventions to reduce the experience of internalized stigma in the population of adults with severe and persistent MI living in the community.

\section{Scope and Delimitation}

The scope of the study is to determine the influence of self-stigma on persons with MI occupational engagement. The researchers sought to learn of the effects of self-stigma on occupational engagement and to inform OT practitioners of the importance of addressing selfstigma during intervention. Delimitations of the study include sample and data collection from one location, utilization of theoretical framework, and transparency through the data analysis

process. The sample and data collection processes from one location was determined necessary by the researchers due to time restraints. The researchers transparency parameters were implemented to establish trustworthiness for reliability and validity of the results; these transparency parameters were established and required increased attention to details throughout data collection and analysis. Other options available to evaluate the effects of self-stigma may have included focus groups, or surveys. In the essence of time and availability of willing subjects, individual interviews were conducted. The EHP model was utilized to provide parameters for guidance of developing data collection tools, and the process of data analysis. EHP provided parameter considerations for person variables, contextual information, and task analysis, each of which can be influenced by the effects of self-stigma. 


\section{Operational Definitions}

- Stigma: generalized public beliefs (often negative connotations) of persons with mental illness (example: all persons with mental illness are dangerous and unpredictable, therefore, they are to be feared) (Corrigan, 2000).

- Self-stigma: internalized negative beliefs of public stigma (example: I have a mental illness and am unpredictable and should be feared) (Corrigan, 2000).

- Occupation: everyday life activities (American Occupational Therapy Association [AOTA], 2014).

- Task: parts of activities completed to reach an ultimate goal (Dunn et al., 1994).

- Performance range: degree to which a person utilizes their skills and capabilities to complete tasks in the environment (Dunn et al., 1994).

- Occupational engagement: the act and process of completing meaningful occupations in varying contexts (AOTA, 2014)

- Contexts: varying environmental considerations in which tasks are completed. Ranging from cultural to social to physical and temporal (Dunn et al., 1994).

\section{Organization of Remaining Chapters}

Chapter 2 will review the existing literature on public stigma and self stigma. The literature review addresses the gap in occupational therapy literature which serves the purpose of the current study. Chapter 3 describes the methodology utilized to conduct the study. Included in this section are the parameters of the study. The process of data analyses is also described in Chapter 3. Chapter 4 is comprised of the results of the study, including: codes, categories, themes, structural/textural descriptions, and one final assertion. Also included within Chapter 4 
is the discussion of the results. Chapter 5 is a summary of the findings and limitations with recommendations for future research. 


\section{CHAPTER 2}

\section{LITERATURE REVIEW}

\section{Introduction}

Public stigma has clear detrimental effects on persons with MI, including self-esteem, social inclusion, and relationships with friends and family. The construct of self-stigma and the effects on the individual, ways of measuring self-stigma, and interventions to minimize the effects on the individual will be described.

\section{Public Stigma}

First defined by Goffman (1963), public stigma towards persons with mental illness (MI) is the cultural prejudice and negative attitudes often resulting in bigotry and discriminatory actions (Corrigan, 2000). The existence of public stigma persists through institutional and social forces at two levels: intentional and unintentional (Corrigan et al., 2004). The institutional forces depicted as intentional include specific limitations in regards to social justice of individuals with MI. Examples of these institutional forces include limitations in their right to vote, unequal marital rights, and perceived inability to raise a child according to the law.

Thornicroft, Rose, Kassam, and Sartorius (2007) describe the injustices indicated as initial prejudices that lead to discriminatory behavior illegitimately restricting equality for persons with MI. Prejudice beliefs often comprise an emotional component, leading to intentional discriminatory responses, and jeopardizing individuals with MI quality of life due to constant social defensiveness or avoidance (Corrigan \& Watson, 2002; Crocker, Major, \& Steele, 1998). Discriminatory action from society has been reported to prevail against individuals with 
MI's quality of life by limiting work, education, and social opportunities, as well as compromising their self-esteem and psychological well-being (Corrigan, 1998; Corrigan \& Watson, 2002; Major \& O’Brien, 2005; Pescosolido, Medina, Martin, \& Long, 2013).

The unintentional social forces present are the preconceived ideas and attitudes expressed by individuals in society (Corrigan, Markowitz, \& Watson, 2004). Often the unintentional assumptions include beliefs that individuals with psychiatric disabilities are responsible for their mental dysfunction, characterized as weak, dangerous or violent, and unpredictable, and irresponsible to lead independent 'normal' lives (Angermeyer \& Dietrich, 2006; Boysen \& Vogel, 2008; Corrigan \& Watson, 2002; Peluso \& Blay, 2009). Endorsed public stereotypes, specifically the prejudice that all persons with MI are dangerous, has been shown to minimize work opportunities due to social avoidance of persons with psychiatric disabilities (Corrigan, Powell, \& Rusch, 2012).

Recent attitudinal surveys of societal perceptions of individuals with psychiatric disabilities reveal inconclusive results. According to Thornicroft et al. (2007), a decrease in negative presumptions was noted in population surveys from previous surveys. Hinshaw and Stier (2008) found a heightened negative response towards individuals with psychiatric disabilities in the past decade. Boysen and Vogel (2008) found that if individuals in society held negative perceptions and blamed the person with MI for their diagnosis, subjects' attitudes were less likely to alter even after intervening with education and anti-stigma campaigns. These results prevail the importance of assimilating persons with MI into society to prevent disparities from occurring. 
The contradicting results imply cyclical deprivation of individuals with MI opportunities in society as well as placing them at higher risk for internalizing negative presumptions. A problem with cyclical deprivation that individuals with MI experience is avoiding healthcare treatment. Ben-Zeev, Young, and Corrigan (2010), describes the health care avoidance form of stigma, known as label avoidance, which is depicted as deterring one's self from seeking healthcare to avoid the label of a "mental patient." Avoiding the label of "mental patient," leads to a decreased aptitude for persons with MI to seek healthcare services and adhere to treatment (Corrigan, 2004). This lack of adherence to treatment during times of crisis, lead to occasions when persons with MI could receive adequate treatment from a healthcare team; however, often police are called upon for assistance (Teplin, 1984; Watson, Corrigan, \& Ottatti, 2004). Increased response from the police force leads into an inaccurate depiction of persons with MI in the media; furthering the perception in society that persons with MI are to be feared (Clarke, 2004; Teplin, 1985).

Surveys of persons with MI conducted by Angermeyer and Matschinger (2003) and earlier by Corrigan (1998) found that perceived personal attributes, and negative emotions towards adults with MI led to social distancing. This social distancing inadvertently limits persons with MI opportunities for personal goal attainment. Knights, Wykes, and Hayward (2003) found that adults with MI reported commonalities of stigmatization such as constant judgement, comparing themselves to others, and discrepancies understanding the complexity of their illness.Ultimately this leads to discord amongst each area of their lives in which social encounters occurred, including with family members (Corrigan \& Miller, 2004; Perlick et al., 2001). 


\section{Effects of Public Stigma on Families}

Limited research has been conducted in regards to the stigmatization experienced by family members related to persons with MI. However, a term coined by Goffman (1963) courtesy stigma- represents the stigmatization associated with family members of persons with MI. In Wahl and Harmon's (1989) study, 56\% of family members of persons with MI reported being influenced by negative stigmatizations from their relative's diagnosis of a MI. Larson and Corrigan (2008), Corrigan and Miller (2004), and Corrigan, Watson, and Miller (2006), found that shame, avoidance, guilt, and diminished social supports often accompany a family member's mental health diagnosis. Shame is delineated into two cognitive-behavioral responses: blame and contamination (Corrigan \& Miller, 2004). Often, family members are blamed, or their sense of self is contaminated due to the encounters with their loved one who has a diagnosis of MI (Larson \& Corrigan, 2008). However, although social supports such as friends, and other affiliations through the community altered following their family members psychiatric diagnosis, tangible aspects such as their work and housing stability were not influenced. Interestingly, individuals who actually had a diagnosis commonly would be negatively affected in work and housing due to stigmatization effects (Angermeyer \& Matschinger, 2003; Corrigan \& Watson, 2002).

\section{Effects of Public Stigma on Sense of Self}

Stigmatization has been found to influence persons with MI's sense of self in relation to self-esteem, self-efficacy and overall quality of life (Markowitz, 1998; Rosenfield, 1997). Rusch et al., (2009) found that individuals who experience emotional stress secondary to public stigma often display feelings of hopelessness, low self-esteem, and negative self-concept, which further impacts their capacity to seek employment, relationships, and housing. Ilic et al.'s (2011) study 
of persons with MI self-esteem found that as individuals with MI experience others' withdrawal after 'coming out' about their illness, their self-esteem seriously decreased. The association between verbalizing one's MI and society's withdrawal reaction leads to further social isolation and compromising goal attainment. Alteration in personal self-perception after receiving a diagnosis of MI was also found to lead to social isolation (Lloyd, Sullivans, \& Williams, 2005). Both intentional and unintentional forces of public stigma lead to internalization of negative connotations for persons with MI, otherwise known as self-stigma (Hinshaw \& Stier, 2008). Self-stigma is suggested as further impinging upon individuals with MI's pursuit of life goals (Corrigan \& Watson, 2002).

\section{Theoretical Models of Public Stigma}

Several models are available to aide in addressing public stigma. Martin, Pescosolido, Olafsdottir, \& McLeod's (2007) proposed a model known as Etiology and Effects of Stigma Model (EES) as an attempt to disassemble the entanglement of public stigma. The model outlines the belief that sociodemographic variables of the person with MI and another person without a MI both bring experiences and perceptions towards interactions which changes societal perceptions of persons with MI.

Corrigan (1998), presents the model The Impact of Stigma and Discrimination, representing the delineation of events that occur once a person with MI experiences an exacerbation of symptomatology, and subsequent misperceptions of the diagnosis.

Misperceptions lead to discriminatory actions towards persons with MI and a decreased quality of life. Additionally, attribution theory has commonly been utilized in mental health research to describe how stigma is formulated based on society's perceptions that persons with MI have control over their symptomology, which leads to prejudiced beliefs about their potential in life 
(Boysen \& Vogel, 2008; Corrigan, 2000; Hinshaw \& Stier, 2008). Each of the theoretical models described have been used to guide research and treatment for persons with MI.

\section{Assessments for Public Stigma}

Numerous assessments have been produced to evaluate the presence of public stigma experienced by persons with MI and held by persons in society. Corrigan, Gause, Michaels, Buchholz, and Larson (2015) conducted a study to review the psychometric and sensitivity properties of the California Assessment of Stigma Change (CASC) to evaluate public stigma held by society. The results indicated that the CASC showed minimal internal validity in deciphering the changes of perceptions of persons with MI held by persons in society. The validity of two stigma scales, Devaluation and Discrimination scale, and Rejection experiences scale, produced to evaluate the public stigma experienced by persons with MI, were shown to present high levels of internal consistency (Bjorkman, Svensson, \& Lundberg, 2007). Clearly, although multiple measures have been developed, differences in utility and worthiness exist.

\section{Interventions for Public Stigma}

Although literature discusses the barrier of public stigma, limited research pertains to effective interventions to minimize the presence of stigma (Watson \& Corrigan, 2005). Research between the 1980's-early 2000's emphasized primarily educational aspects of mental illness to intervene and alter public stigma. More recently, however, Pescolido, Medina, Martin, and Long (2013), asserted that society understands the etiology and biological model of mental illness and recommend interventions to change public stigma focus instead on education of inclusion aspects of persons with MI. Educating society of how to support inclusion of all persons with MI in employment, education, and social aspects becomes the focus (Corrigan \& Rao, 2012). 
Current literature suggests three main approaches to minimizing public stigma. These approaches include: protesting, educational information pertaining to societal inclusion, and contact (Corrigan, \& Watson, 2002; Corrigan, \& Penn, 2015; Corrigan, \& Wassel, 2008; Watson \& Corrigan, 2005). The protest approach is hypothesized to withdraw negative perceptions of MI through anti-stigma campaigns (Corrigan \& Watson, 2002). Protest approaches often lead to minimal or only short term effects in reducing public stigma (Corrigan et al., 2001; Corrigan \& Penn, 2015); whereas education (inclusional aspects) and contact, increased positive ideation of persons with MI. The contact approach is described by Corrigan (2011) with five principles to consider to minimize public stigma through social contact of persons with MI. The principles are: 1. contact is fundamental, 2. contact must be targeted, 3. local contact programs are more effective, 4. contacts must be credible, and 5. contact must be continuous (Corrigan, 2011).

The principles emphasize the importance of physical and social contact, targeting contact approaches to persons in power, aiming those targets to a specific location with consideration of the geographic aspects, identifying demographic similarities between the persons with MI and the persons in power (i.e. similar career pathways), and increasing the frequency of contact (Corrigan, 2011). Enhancing social encounters of persons with MI has shown to have an inverse relationship with endorsed stigmatizing attitudes (Holmes, Corrigan, Williams, Canar, \& Kubiak, 1999; Corrigan et al., 2001). These results depict the importance of increasing social encounters of persons with MI to decrease societal stigma.

Although intervening in regards to public stigma is crucial, the detriments associated with internalizing public stigma for persons with MI deserves to be addressed. The detriments of internalized stigma will be discussed in detail below. Vogel, Bitman, Hammer, and Wade (2013) in a longitudinal study of internalized stigma for persons with MI over a decade, found that 
public stigma serves as a direct barrier towards persons with MI establishing a positive sense of self while building upon their attributes for employment, housing, and social relationships.

Overall, endorsed public stigma may serve as a potential barrier to personal goal attainment due to the internalized aspects for the person with the mental health diagnosis (Vogel, Shechtman, \& Wade, 2010). Markowitz (1998, p.344) posed a statement in regards to the process of internalized stigma: "Mentally ill persons may expect, and experience, rejection in part because they think less of themselves, have limited social opportunities, and resources and because of the severity of their illness."

\section{Self-Stigma}

Self-stigma occurs as a result of the stereotypes, prejudice, and discrimination towards individuals with MI that are endorsed by the public (Corrigan, 2000). This construct is a component of the modified labeling theory approach to mental disorders introduced by Link, Cullen, Struening, Shrout, \& Dohrenwend (1989). Individuals develop negative perceptions of what it means to possess a diagnosis of mental illness based upon public beliefs and begin to internalize these viewpoints as a component of the process of this theory (Link et al., 1989). Social psychologist theories propose a model in which individuals who determine their diagnosis of MI to be a significant component of their character and identify with the negative stereotypes present are likely to experience harmful effects on overall well-being (Aronson et al.,1999; Steele et al., 2002).

\section{Prevalence of Self-Stigma}

Literature is limited to determine the effects of this phenomenon on a global scale, however, researchers have recently explored the extent to which self-stigma has impacted individuals with affective and psychotic disorders within 14 European countries (Brohan et al, 
2010b; Brohan et al. 2010a). Approximately one fifth of individuals with affective disorders indicated experiencing a moderate to high level of self-stigma with high levels of perceived discrimination also reported. Nearly one half of individuals with psychotic disorders living in European countries experienced moderate or high levels of self-stigma (Brohan et al., 2010a).

Corrigan, Rafacz, and Rusch (2011) developed and examined a progressive theoretical model to determine how self-stigma affects individuals diagnosed with MI applying the stages of awareness, agreement, application, and harm (Corrigan, et al., 2011; Corrigan et al. 2006). Utilizing this model as a theoretical basis, individuals with MI become aware of negative beliefs held by the public, agree with these beliefs, apply these to themselves, and further harm selfesteem as a result of this process (Corrigan et al., 2011). A majority of the effects of self-esteem and hopelessness within the individual are associated with the application and harm phases within this model in comparison to the awareness and agreement stages (Corrigan et al., 2011; Corrigan et al, 2006; Corrigan \& Rao; 2012; Corrigan et al. 2009). Individuals who are aware of stereotypes but do not accept the stigma of persons with MI are likely to react with indifference and less likely to be affected by self-stigma (Corrigan \& Watson, 2002; Michalak et al., 2011)

\section{Effects of Self-Stigma on the Individual}

Research has been conducted across disciplines to explore the effects of self-stigma on individuals with mental illness, resulting in several hypotheses. Corrigan and Watson (2002) proposed the situational paradox reaction model, which considers the various reactions of individuals with MI to stigma. Upon awareness of social stigma present in society, individuals may react in a way that energizes their anger and provokes personal empowerment to overcome these stereotypes and achieve personal goals and success (Corrigan, Larson, \& Rusch, 2009; Corrigan \& Watson, 2002). Conversely, the internalization of stigma may cause the individual to 
experience detrimental effects on self-esteem and self-efficacy (Link et al, 2001; Corrigan \& Watson, 2002; Corrigan, Watson, \& Barr, 2006; Yanos et al., 2008; Corrigan et al., 2009; Rusch et al., 2010).

Despite the documented varying reactions that may occur within persons with MI, the most prevalent response to self-stigma leaves individuals feeling susceptible to feelings of being devalued and discredited members of society (Livingston \& Boyd, 2010). In addition to diminished self-esteem and self-efficacy, feelings of isolation and alienation of individuals with MI are likely to occur as a result of self-stigma (Ritsher \& Phelan, 2004; Perez-Garin, Molero, \& Bos, 2015). Lower morale, lower satisfaction, and lower overall meaning and quality of life have additionally been noted to occur within individuals who experience self-stigma (Ritsher \& Phelan, 2004; Switaj, 2014; Ehrlich-Ben et al., 2013; Rusch et al., 2010). The effects of selfstigma are situational, however, persons with MI are more likely to experience detrimental feelings and responses associated with self-stigma if previous incidents of discrimination have occurred in the individual's life (Quinn, Williams, \& Weisz, 2015). An individual's increased amount of experiences with discrimination in the past leads to higher anticipation of future discrimination, which subsequently facilitates the belief that others will devalue persons with MI (Quinn et al, 2015).

Implications of the effects of self-stigma on persons with MI have assisted in developing the complex construct of the "why try effect" (Corrigan et al, 2009). Internalization and application of the stereotypes associated with MI resulting in diminished self-esteem, selfefficacy, and empowerment further negatively impact an individual's pursuit in life goals and willingness to seek healthcare services (Corrigan et al., 2009; Corrigan, 2004). The attitudes 
associated with this construct often lead to social avoidance and selective disclosure of one's diagnosis of MI (Corrigan et al., 2009).

\section{Measuring Self-Stigma}

Several measures have been utilized to develop a greater understanding of the impacts of self-stigma on the individual (Brohan, Clement, \& Thornicroft, 2010; Mittal et al., 2012). Assessments of self-stigma address cognitive, affective, and behavioral responses to the stigma perceived by the individual (Brohan et al., 2010c). In a comprehensive review of literature, Mittal et al. (2012) identified the Perceived Devaluation and Discrimination Scale (PDD), the Internalized Stigma of Mental Illness Scale (ISMI), and the Self-Stigma of Mental Illness Scale (SSMIS) as the only measurement tools utilized by researchers that are grounded in conceptual frameworks (Mittal et al, 2012, Brohan et al, 2010c). The PDD is a 12 item self-complete measurement tool in which individuals rate each item of devaluation and discrimination on a sixpoint Likert scale (Mittal et al, 2012). This assessment tool has been developed based up the framework developed by Link (1987), however, there is a necessity for further research to be conducted to determine the effectiveness of this scale.

The ISMI is a self-report subscale that measures an individual's experiences with selfstigma through categories of alienation, stereotype endorsement, discrimination experience, social withdrawal, and stigma resistance (Ritsher, Otilingam, Grajales, 2003). Each of the subscales of the ISMI has demonstrated excellent internal consistency reliability, test-retest reliability, concurrent validity, and divergent validity (Ritsher et al., 2003; Brohan et al., 2010; Chang et al., 2014). A user friendly, 10-item brief version of the ISMI has recently been developed from the original 29-item assessment (Boyd, Otliingam, \& DeForge, 2014). The brief version of the ISMI has exhibited adequate internal consistency reliability and external validity, 
determining this tool as a practical measurement in comparison to the 29-item scale (Boyd et al., 2014).

Similar to the ISMI, the SSMIS is a self-report measurement tool that consists of four levels including, stereotype awareness, stereotype agreement, self-concurrence, and self-esteem decrement (Corrigan et al., 2006). Developers of the SSMIS have recently shortened this scale to measure 20 items within the 4 levels in comparison to the original 60 items (Corrigan et al., 2012). Items were omitted from the SSMIS after feedback from consumers of the most offensive statements within this assessment (Corrigan et al., 2012). The original version of the SSMIS as well as the short form have both been determined to exhibit internal consistency, construct validity, and test-retest reliability (Brohan et al., 2010c; Corrigan et al., 2012).

Vogel, Wade, and Haake (2006) developed a tool to measure the effects that self-stigma has on a person's decision to engage in mental health services in a similar timeframe of when the ISMI was developed. The Self-Stigma of Seeking Help scale (SSOSH) is a 10-item measurement tool that has been developed through feedback of the original 28 -item assessment over the course of five trials (Vogel et al., 2006). Through this assessment, one is able to obtain an understanding of the individual's level of comfort or concerns associated with seeking psychological help (Vogel et al, 2006). The SSOSH manifested strong internal consistency reliability as well as excellent test-retest reliability (Vogel et al., 2006). Cross cultural examinations of the internal reliability and construct validity has additionally been examined from a sample of six different countries, to which authors determined psychometric properties the SSOSH to be adequate Vogel et al., 2013). 


\section{Interventions for Self-Stigma}

Through utilization of various measurements of self-stigma, researchers have determined the need for a standardized intervention to address self-stigma (Yanos et al., 2008). Numerous approaches have been employed to target the negative effects of self-stigma on individuals with MI, predominantly group-based interventions (Yanos et al., 2015). Cognitive behavioral therapy (CBT) approaches may be beneficial in addressing self-stigma from the standpoint self-stigma as

a result of cognitive distortions (Yanos et al., 2008; Shimotsu, 2014). Narrative enhancement and cognitive therapy (NECT) is a 20 session group-based intervention that draws from CBT concepts in which persons are to reflect upon their experiences of self and illness over time in comparison to the myths of MI (Yanos, Roe, \& Lysaker, 2011). Other group intervention protocols that have been developed based upon similar concepts include Healthy Self-Concept, the Self-Stigma Reduction Program, the Ending Self-Stigma, (McCay et al., 2007; Fung et al., 2011; Lucksted et al., 2011).

More recent in the literature, the Anti-Stigma Photovoice program, a peer led intervention, was developed by Russinova et al. (2014), which incorporated the strategy of taking pictures, recording narratives, and reflecting upon participant experiences. Unlike the previous interventions described, the Coming Out Proud program was developed upon theoretical designs from other stigmatized groups such as the Lesbian, Bisexual, Gay, Transgender, and Questioning (LBGTQ) communities (Corrigan, Kosyluk, \& Rusch, 2013). The intervention consists of only three group sessions in comparison to other tested protocols (Corrigan et al, 2013). The intent of this intervention is that disclosure of one's MI will empower the individual to overcome effects of self-stigma (Corrigan et al., 2013). 


\section{Self-Stigma in Occupational Therapy Literature}

While multiple disciplines have examined the effects of self-stigma on persons with MI, assessment tools to measure the effects, and interventions to overcome internalized stigma, limited research has been published in occupational therapy literature. Caltaux (2002) is at this time, the only researcher within the occupational therapy profession to consider the effects of self-stigma on individuals with MI. Based on a review of the literature, Caltaux (2002) determined that individuals who experience self-stigma are faced with self-imposed barriers which may affect all aspects of a person's life. Health professionals are encouraged to be aware of the impacts of self-stigma in order to effectively support persons with MI and support reduction of internalized stigma (Caltaux, 2002).

\section{Problem Statement}

In professions such as psychology and nursing, self-stigma has been found to negatively impact the quality of life (QoL) of persons with MI. However, to the researchers' knowledge, evidence in the profession of occupational therapy regarding the effects of self-stigma on occupational enagement of adults with MI, has not been pursued. The negative effects on selfesteem and self-efficacy identified in other professions and the OT literature associated with selfstigma leads to the purpose of the current study. 


\section{CHAPTER 3}

\section{METHODOLOGY}

\section{Research Purpose}

The purpose of this study is to explore the impacts of self-stigma on everyday occupations of persons with serious and persistent mental illness. Greater understanding of the impacts of self-stigma is important to development of occupation-based interventions used by occupational therapists in mental health settings.

\section{Qualitative Research Design}

A qualitative research design was utilized in order to explore the experiences of selfstigma on occupational engagement for adults with mental illness. Specifically, the qualitative nature of the design served a purpose to determine the possible effects of self-stigma on occupational engagement in a semi-structured interview. Moustakas (1994), the founder of phenomenological research, described the value of a phenomenological qualitative design to understand the lived experiences of individuals. Review of the literature revealed a study conducted by Raphael-Greenfield and Gutman (2015) utilized a phenomenological, qualitative approach with a population of similar interest as this study; results of the study demonstrated effectiveness of the phenomenological approach. Therefore, components of their research design were used to guide implementation in this study. Data interpretation was completed using methods developed by Madison (2005). 


\section{Role of the Researcher}

The researcher serves as an instrument to further enhance the depth of the interview to generate data (Xu \& Storr, 2012). The researchers served the purpose of providing an inside view (emic) of the experienced lived by adults with MI and their experiences with self-stigma (Simon, 2011). Additionally, the researchers served the purpose of being a human instrument to depict self-stigma experienced by individuals through data collection and analysis. To stay close to the data, researchers did not utilize any computer software. Additionally, each component of data collection and data analysis was conducted by both of the researchers to assure connectedness between the data and findings.

\section{Unit of Analysis}

The unit of analysis was at the individual level. The participants of this study were adults with MI receiving services at a community-based mental health setting, Prairie Harvest Mental Health (PHMH) in Grand Forks, North Dakota.

\section{Sources of Data}

Recruitment occurred through the researcher's attendance at a bi-weekly meeting for adults living and participating in the lodge programs at PHMH. The researchers printed copies of recruitment fliers (Appendix A) and distributed them to each attendee and the meeting coordinator for further recruitment of participants, if needed. Contact information for participants was provided through the meeting coordinator via phone calls with the researchers after the meeting to recruit a total of 6 participants.

\section{Locale of the Study}

Participants were offered the option of participating in the interview in either their home or in a private office space at PHMH. Each participant requested the interviews to be conducted 
in the privacy of their home. Interviews were conducted 1:1 with the researcher and participant in the comfort of their home. Options were offered to the participants to provide a sense of comfort and ease to facilitate a safe, open, and nonjudgmental environment during the interview.

\section{Population and Sampling}

Data was collected from clients affiliated with PHMH. PHMH provided consent, verbally and written, to recruit participants (Appendix B). Convenience sampling was utilized to recruit participants (Marshall \& Rossman, 1999). Inclusion criteria consisted of a mental health diagnosis, adults 21+ years of age, English speaking/comprehension, and living in the community, but affiliated with PHMH. Exclusion criteria included presence of psychosis or mania, or a legal guardian. Six participants were recruited; four of the six were diagnosed with schizoaffective disorder and two were diagnosed with bipolar disorder. Each of the six participants had also previously experienced substance abuse and/or aspects of anxiety or depression.

\section{Instrumentation and Data Collection}

A semi-structured interview schedule was developed based on a review of literature regarding self-stigma conducted in the past decade. Questions in the general interview approach were developed based on the Patton Model (1990), which includes questions of behavioral and emotional nature, personal background experiences, and opinion/value considerations. Utilization of this model to develop interview questions is recommended by Madison (2005), whose methods guided data interpretation for the research study.

\section{Trustworthiness}

Trustworthiness was established through various approaches to provide credible, transferable, dependable, and confirmable results. Triangulation, prolonged engagement, peer 
debriefing, and member checks was utilized to establish credibility. Data was analyzed by the two main researchers, as well as, one advising researcher to establish investigator triangulation and assure honest, logical emerging concepts in the data (Lincoln \& Guba, 1985). Prolonged engagement occurred through immersion of the researchers in the culture of public and selfstigma. Weekly peer debriefing with the advising researcher occurred throughout the course of data analysis and the study as a whole to remain objective in findings (Lincoln \& Guba, 1985).

Member-checking was conducted 2 months following compilation of interview transcriptions and again one-week after the results of the study were finalized. Implementation of recommendations following the member-checks occurred 1 week upon receipt of the feedback from participants. Transferability was established through providing clear, thick, descriptive information including quotes to link the information from data collected to the results (Lincoln \& Guba, 1985).

Establishment of dependentability occurred through inquiry audit from the researchers' advisor on a weekly basis (Lincoln \& Guba, 1985). Finally, confirmability was established through use of an audit trail (Appendix G) to provide a structure for inclusion of records throughout data analysis (Lincoln \& Guba, 1985). The framework utilized to structure our data was modified from Halpern's (1983) recommended audit trail format. The primary researchers completed reflexive journaling following each interview to prevent bias from imposing on accurate depiction of the results of the data, as recommended by Lincoln and Guba (1985). IRB approval occurred through the University of North Dakota; data was collected between August 15th 2015 to September 9th 2015. 


\section{Tools for Data Analysis}

Data was coded utilizing Madison's (2005) in vivo high level coding approach then analyzed using theorized principles developed by Moustakas (1994). Researchers first approached data by completing epoche, which consists of self-reflecting upon the researcher's own experience with self-stigma prior to collecting data, followed by horizonalization statements, or seeing each statement as relevant to the research question as having equal value (Moustakas, 1994). Horizontalizing statements are significant comments verbalized by participants during data collection of how the phenomenon of self-stigma was experienced (Moustakas, 1994).The horizontalizing technique consisted of highlighting important commentary verbalized by each participant after the transcriptions were completed and prior to completing coding of each interview. Using high level coding, data was organized to cluster abstract ideas into in vivo codes. In vivo codes are one-worded or short representations of information present in the data verbalized by participants (Madison, 2005).

The codes documented by the researchers were then clustered and further organized for comparison (Madison, 2005). Each of the two researchers independently utilized Madison's coding technique to code the interview transcriptions of the interviews conducted. Each of the researchers conducted 2 interviews per participant, and 3 participants per researcher for a total of 6 interviews per researcher, and a total of 12 between the two researchers. After the researchers coded the interviews they had conducted, they independently reviewed their research partner's transcriptions and again coded those transcriptions individually utilizing Madison's coding technique. After all 12 interviews were coded by each researcher independent of one another, both researchers created categories utilizing all of the codes from each of the interviews following Moustakas's (1994) recommendations for identification of categories. Appendix H, is 
provided as a visual aid to present the organization of the codes in each category; 639 codes were categorized into 23 categories. Upon comparison and further organization, 4 themes evolved to present the underlying meaning of data (Moustakas, 1994).

After determining the themes, textural descriptions of the experience of self-stigma for persons with MI were created. Textural descriptions present the "what" meanings and conclusions of the phenomenon of self-stigma for individuals with MI in regards to occupational engagement (Moustakas, 1994). After formation of textural descriptions, the structural description of the data was formulated. Structural description is the "how" of the phenomenon of self-stigma for persons with MI (Moustakas, 1994). Finally, a composite description of the textural and structural statements was written to present a final assertion of data to represent the essence of the effects of self-stigma on occupational engagement for adults with MI (Moustakas, 1994). 


\section{CHAPTER 4}

\section{ANALYSIS AND INTERPRETATION OF DATA}

\section{Analysis of Data}

The purpose of the study was to evaluate the effects of self-stigma on occupational engagement for adults with mental illness (MI). A phenomenological approach was utilized to guide the qualitative study. Data was analyzed through theorized principles of Moustakas's (1994) approach to conducting phenomenological research, and Madison's (2005) high level coding technique. This approach was utilized in this study due to the credibility of methods developed by Moustakas.

Horizontalization statements were utilized to highlight important commentary verbalized by participants. High level coding was then utilized to organize abstract ideas into in vivo codes, which are short representations of information verbalized by participants (see Appendix $\mathrm{H}$ for a full list of codes). Codes were then clustered for further organization and comparison into categories (Madison, 2005) . Refer to Table 4.1 for a full list of categories with the corresponding list of codes. 
Table 4.1

\begin{tabular}{|c|c|}
\hline Categories & \# of Codes \\
\hline Emotional expression & 55 \\
\hline Symptoms of MI & 50 \\
\hline Previous life experiences & 49 \\
\hline Societal impact & 40 \\
\hline Negative sense of self & 40 \\
\hline Future goals & 34 \\
\hline Coping with negative social encounters & 33 \\
\hline Life views & 32 \\
\hline Governmental affiliations & 31 \\
\hline Self care & 30 \\
\hline Life after diagnosis with MI & 26 \\
\hline Friend/relationship impacts & 25 \\
\hline Family & 25 \\
\hline Substance abuse & 25 \\
\hline Hobbies/interests & 24 \\
\hline
\end{tabular}




\begin{tabular}{|l|l|} 
Values & 21 \\
\hline Employment & 17 \\
\hline Positive responses to MI & 16 \\
\hline Acts of diminished sense of self & 16 \\
\hline Education & 16 \\
\hline Positive sense of self & 13 \\
\hline Self isolation & 12 \\
\hline Personal convictions & 9 \\
\hline Total: 23 & Total: 639 \\
\hline
\end{tabular}

Four themes emerged from the categories: negative impact on self, coping with negative social encounters, positive contributions to one's sense of self, and acceptance of diagnosis and acknowledged need for medication. Structural and textural descriptions were then created to represent the experiences of persons with MI. Refer to Table 4.2 for a complete listing of the textural and structural descriptions corresponding with the themes presented. 
Table 4.2

\begin{tabular}{|l|l|}
\hline Themes & Textural/Structural Descriptions \\
\hline Negative impact on self & $\begin{array}{l}\text { Initially receiving a mental health diagnosis } \\
\text { influenced one's sense of self negatively } \\
\text { which influenced social relationships, } \\
\text { employment, and ability to cope adaptively } \\
\text { without use of substances. }\end{array}$ \\
\hline Coping with negative social encounters & $\begin{array}{l}\text { Learning to cope with negative social } \\
\text { encounters in one's life after diagnosis led to } \\
\text { refinement or maintenance of future goals, life } \\
\text { views, and occupational participation. }\end{array}$ \\
\hline Positive contributions to one's sense of self & $\begin{array}{l}\text { Life experiences and support from mental } \\
\text { health service providers, family, and friends } \\
\text { over time altered one's sense of self positively } \\
\text { and led to awareness of valued occupations. }\end{array}$ \\
\hline Acceptance of diagnosis and acknowledged & $\begin{array}{l}\text { Acceptance of the diagnosis and } \\
\text { acknowledgment of a need for medication } \\
\text { management to alleviate symptoms of their } \\
\text { mental illness improved one's occupational } \\
\text { engagement. }\end{array}$ \\
\hline need for medication &
\end{tabular}

One assertion was then presented to represent the essence of the effects of self-stigma on occupational engagement for adults with MI: Self-stigma is experienced as changes in sense of self with the greatest impact shortly after the initial diagnosis of the mental illness; with time and external supports, the individual learns to accept and cope with the diagnosis, resulting in decreased self-stigma and increased occupational engagement.

Participants in this study included four males and two females, all of Caucasian descent and ranging in age from 31-58 years old. The number of years affiliated with community supportive housing at Prairie Harvest Mental Health (PHMH) ranged from 1 year to 10 years. All participants had extensive histories of substance use ranging from illicit drug use to alcohol 
abuse, as well as psychiatric diagnoses including bipolar disorder type I, schizoaffective disorder, depressive disorders, anxiety disorders, post-traumatic stress disorder (PTSD), and personality disorders. Four thematic categories emerged during interview analysis: negative impact on self, positive contributions to one's sense of self, coping with negative social encounters, and acceptance of diagnosis and acknowledged need for medication. These themes expressed the lived experience of the participants and internalized stigma that influenced their daily occupational participation. In the presentation of themes which follows, participants are identified by pseudonyms in order to present quotations anonymously. The following names are used: Annie, Bryce, Charlie, Dylan, Ernie, and Francis.

\section{Themes}

\section{Negative Impact on Self}

Four of the six participants expressed alterations in perceptions of themselves as a result of internalizing stigma associated with their MI. Francis discussed the impact of societal views of herself and MI in her daily life, "You become what you are told, often." These views were reported as leading to influencing one's self-worth, as Annie mentioned, "I used to think I was worth nothing, and I'd focus on my mistakes. "Francis reiterated the effects of internalizing societal beliefs, “I thought I was a failure. The self-talk. I thought you can't do that. You will never amount to anything...the fear of failure keeps me from pursuing goals and everything." Initially receiving a mental health diagnosis influenced one's sense of self negatively, which influenced social relationships, employment, and ability to cope adaptively. Francis described her skepticism with participating in social relationships, "They treat me differently. Like they know the word crazy isn't appropriate but it's a word that is often used and stuff and ... in society and people think that when you have a mental illness that you are dangerous and they 
always think that you are going to go off at any given time and have a breakdown and ... they don't know they don't trust you...there is a lot of for me shame. And I feel misunderstood." Employment was reported as a major area of life influenced by internalized negative beliefs; Ernie described the conundrum associated with not participating in the army because of his selfperceptions: "I felt like I got branded. See after high school I was planning on joining the army. And when I (was) 17, I was like whoa they ain't gonna want me now. I'm not even good enough to take a bullet for this country. You know that's how I kind of felt."

\section{Coping with Negative Social Encounters}

Learning to cope with negative social encounters in life after diagnosis led to refinement or maintenance of future goals, life views, and occupational participation. Initially, participants reported negative emotional responses towards social interactions with others presumably knowing about their mental illness. Annie described difficult experiences in her childhood, "I was very lonely, and I — especially in the school years...you know, kids can be so mean. But then you grow up and you become an adult and you learn how to look at that person, and if they're giving you looks...or if you suffer from depression, that says more about them than it says about you." Social encounters were described by participants as requiring them them to learn how to emotionally distance themselves from the negative aspects of stigma. Ernie discussed his perception of society's views of people with MI, "Well more recently I have seen things a little bit different. But since 17 it's been like, no one even in the real world, gives a shit about people with a mental illness." Ernie also described how he has learned to adapt to societal perceptions of persons with MI, "I am just finding out that some people the more you educate they ain't going to change their opinion and they won't change their opinion. And that is just how it is." Over time, the emotional disconnect that participants presented to cope with social experiences lead to 
refinement of goals involving social interactions. Charlie described his improvement of managing social encounters over his lifetime, "Why try to go to school every day and why try to... blend in with this crowd of people that are supposedly my friends when I know they're laughing about me right when I leave the room...that was a long struggle, and I'm sure glad I'm out of that struggle. But I can't even remember what that feels like right now, it's been so long."

\section{Positive Contributions to One's Sense of Self}

"Life is the way that it is, it is what it is. Whatever happens in it, well it is over an' done with." This statement was verbalized by Ernie as he described how he has learned to view himself in a positive way. Life experiences and support from governmental affiliations, family, and friends over time altered sense of self positively and led to awareness of valued occupations. Participants reported experiences of living with mental illnesses as being a main factor in shaping who they are today. Ernie indicated, "Well you know growing up with it [MI], learning about it $[\mathrm{MI}] . . . \mathrm{I}$ think it has built some character actually." Participants reported that at times, maintaining a positive sense of self can be a struggle, yet they have intrapersonal skills to remind themselves of the meaningful aspects in their life. Charlie shared his experiences of remaining mindful of the meaning in his life, "Sometimes you think, God I wish I had his lifestyle. Like, when I think of one of my brothers or something, you know? ... But then I think back to reality, and I'm doing the best from where I'm sitting with the resources I've got." Bryce described the importance of having a social support system in his life which contributes to his positivity, "I moved to (this town) when I was about 30, and I really wasn't interested in meeting and knowing people with mental disabilities... But now, you know, 95\% of my friends are mentally disabled, you know, and that's been nice, because we all get along really good." Participants reported that a sense of maturity aided in decreasing the internalized stigma with their MI. Annie indicated, 
"You know when I was younger and I didn't know what I know now. I just have to remind myself of what I've already accomplished."

\section{Acceptance of Diagnosis and Acknowledged Need for Medication}

Acceptance of a diagnosis and acknowledgment of a need for medication management to alleviate symptoms of mental illness improved one's occupational participation. All participants acknowledged their mental illness as a part of who they are, but verbalized that initially receiving their diagnosis was an emotional battle. Ernie expressed the insight he has gained as a result of accepting his diagnosis, "Well all this time I been fighting this, when I could have been doing something more constructive." Annie also described a similar process to Ernie of emotional acceptance, "I'm so much better now, than I was. I was in bad shape back then, but so many things have happened since then." Francis reiterated the negative emotions that were initially tied to her diagnosis, "There has been a lot of embarrassment attached to this illness for myself and a lot of denial. But I have come to terms with it."

Acceptance was reported to occur in various forms for participants. One participant in particular, Dylan, described how when he received his diagnosis, he was neglecting his duties in his day to day life due to perceived incapacity as a result of his MI. Dylan now has learned to embrace his role expectations and responsibilities, "I just like do the things that she expects me to do. Like clean up and take a shower and make sure everything is alright."

All participants attributed success in acknowledging and managing their MI to mental stability on medication. Participants reported feelings of equality to others in society without MI when feeling mentally stable. Charlie specifically expressed his feelings of contentment and gratitude for medication, "I appreciate the help the meds give me. When I feel them kick in like I am right now, I feel like a complete person just like anybody else out there, you know." 
Medication management in addition to acceptance and acknowledgement of diagnosis was reported to increase all participants' occupational participation and a sense of belonging in society. Bryce described similarities of his mentality to the rest of society, "To tell you the truth, I think in 20 years, like, everyone is going to have a mental illness... I just had a head start on them." The increased insight gained over years of experience and acknowledgement of participants' MI has increased meaning in one's life, occupational engagement, and overall sense of self.

\section{Assertion}

Each participant reported an initial decrease in occupational engagement specifically related to their social relationships, employment, and maladaptive coping with their diagnosis with substances. Occupations noted to be impacted by self-stigma included social participation, employment, medication management, and self-care. Participants coped with negative social encounters (with the occupations noted to have been influenced by self-stigma) through external support from governmental affiliations, family, and friends. Their sense of self immensely improved with these social supports resulting in increased positive sense of self and increased occupational engagement. As this increased positive sense of self occurred, participants reported learning to accept their diagnosis and management of their symptoms through value placed in medication management continued to positively influenced their occupational engagement and pursuance of life goals.

The study findings led to a single assertion: Self-stigma is experienced as changes in sense of self with the greatest impact shortly after the initial diagnosis of the mental illness; with time and external supports, the individual learns to accept and cope with the diagnosis, resulting in decreased self-stigma and increased occupational engagement. 


\section{Discussion}

The research question utilized for guiding this study was to determine the effects of selfstigma on occupational engagement for adults with MI. The research question and corresponding results provide occupational therapy (OT) practitioners with information in regards to the impact of self-stigma on occupational engagement for adults with severe and persistent MI. The results of this study reveal several similarities and differences in the existing literature.

One of the main similarities found between the professional literature and the results of the study was the negative effects of self-stigma on self-esteem and self-efficacy. Link et al, 2001; Corrigan and Watson, 2002; Corrigan, Watson, and Barr, 2006; Yanos et al., 2008;

Corrigan et al., 2009; and Rusch et al., 2010 each found detrimental effects on self-esteem and self-efficacy due to internalized stigma. Corrigan and Watson (2002) developed the paradox reaction model to describe two ways individuals commonly react to public stigma: 1 . Empowerment or energized anger to achieve personal goals; or 2. internalizing the negative aspects of public stigma ultimately leading to diminished self-esteem and lack of goal attainment. The second response correlates with the responses provided by study participants. The occurrence of internalized influences sense of self leading and can lead to lowered morale, personal satisfaction, and overall meaning and quality of life (Ritsher \& Phelan, 2004; 2014; Ehrlich-Ben et al., 2013; Rusch et al., 2010). Rusch et al., (2009) found that individuals who experience emotional stress secondary to public stigma often display feelings of hopelessness, low self-esteem, and negative self-concept, which further impacts their capacity to seek employment, relationships, and housing.

The results of the current study found that diminished self-esteem and lack of goal attainment occurred when initially diagnosed, however, over the years, as the participants aged, 
they reported a sense of empowerment to overcome negative barriers for occupational engagement. This sense of empowerment increased their participation in social relationships and external supports (governmental affiliations, support groups), sustained employment, and managing their medications and replacing maladaptive coping mechanisms to care for themselves. The "why try effect" is one of the barriers identified by Corrigan, Larson, and Rusch (2009) that explains how the internalization of stereotypes impedes the ability to achieve goals and engage in meaningful activities. Participants in the current study reported that as the degree of internalized stigma decreased, they noted an increased meaning in their life which ultimately led to an increase in occupational engagement. Therefore, after years of living with a mental illness diagnosis, the "why try effect" was not discovered to no longer influence the participants' occupational engagement and overall quality of life..

The attitudes associated with public stigma often lead to social avoidance of individuals with a diagnosis of MI (Corrigan et al., 2009). Livingston and Boyd (2010) found that the prevalence of public stigma then leads to reported feelings of being devalued and discredited members of society. Inadvertently, persons with MI report feelings of isolation and alienation as a result of self-stigma related to social avoidance (Ritsher \& Phelan, 2004; Perez-Garin, Molero, \& Bos, 2015). Larson and Corrigan (2008), Corrigan and Miller (2004), and Corrigan, Watson, and Miller (2006), found that shame, avoidance, guilt, and diminished social supports often accompany a family member's mental health diagnosis. While participants of this study described unhealthy relationships with their family, the results were inconclusive to determine feelings of shame, avoidance, and guilt of family members. Participants often reported a time in their life in which they felt devalued by social experiences and alienated from society. However, all of the participants also emphasized their value of overcoming the negative internalized 
thoughts that accompanied the experiences by accepting societal viewpoints of persons with MI. After receiving a diagnosis, support from governmental affiliations and family and friends was reported to contribute to participants' positive sense of self. Over time, the decreased degree of internalized stigma led to acceptance of their diagnosis while caring for themselves (for example, medication management) ultimately leading to increased occupational engagement. The findings of the current study reinforce the importance of encouraging newly diagnosed persons to engage in productively meaningful occupations, as recommended in OT literature. Brown (2011[ZS1] ) in a study of 5 adults with psychosis-related diagnoses found that individuals with early psychosis benefited from engagement in meaningful occupations to empower them to develop a sense of self beyond a diagnosis of a mental illness.

The results of the study at hand found that adults living with severe and persistent MI experienced a higher degree of self-stigma when initially diagnosed in comparison to the present time. Participants' reports of increased occupational engagement and improved sense of self along with acceptance of the diagnosis over time is consistent with the stages of Turner's (1969) Rite of Passage Theory. Turner's theory has been applied to a number of disabilities with particular interest in the second stage of the theory. Turner's three phases present life as a series of transitions. The first phase describes how individuals become separated from the social structure or status as a result of a disabling event in preparation for a new identity. Individuals often view themselves as ill within this stage of transition (Turner, 1969). Study participants described initially receiving their diagnosis as a negative experience that separated them from society. In the second phase of Turner's (1969) Rite of Passage Theory, individuals no longer see themselves as ill, but are likely to struggle with self-identity and role confusion nevertheless. Participants in the study indicated conflicts in sense of self related to their engagement in 
meaningful occupations. They reported negative influences in sense of self specifically in regards to self-esteem and self-efficacy. Role confusion was not reported by participants and was not addressed as a part of the research question. In the third phase of Turner's (1969) theory, individuals disregard labels of "mentally ill" and resolve instances of role confusion to form a new identity. Individuals in this stage of transition are more likely to take medications as prescribed and utilize social and governmental support systems. This final phase of the Rite of Passage Theory coincided with results of this study, as all participants emphasized their gratitude towards PHMH, a service provider, as well as the importance of medication management.

\section{Theoretical Connections}

EHP is an interdisciplinary approach wherein the transactive encounters between a person and the context tasks within performance range are completed (Dunn et al., 1994). The EHP model was utilized to provide parameters for guidance of developing data collection tools, and the process of data analysis. EHP provided parameter considerations for person variables, contextual information, and task analysis, each of which can be influenced by self-stigma.

Application of EHP concepts to the effects of self-stigma showed evidence of the cultural and societal contextual impacts on adults with MI engagement in valued tasks by influencing personal variables. The personal variables most notably influenced by public and internalized stigma were psychosocial aspects of the person. The negative effects found to be associated with internalized stigma included diminished sense of self, self-efficacy, and self-esteem. Task engagement was reportedly influenced when participants were initially diagnosed with a MI, as evidenced by their decreased engagement in tasks such as social relationships, employment, and caring for themselves by maladaptive coping and lack of medication management. 
Yet, with external support (mental health service providers, family, friends) and engagement in meaningful tasks in the social and cultural context, participants' overall task engagement in social relationships, employment, and self-care increased. With this external support from mental health service providers, family, and friends, persons developed coping strategies to counteract the negative effects associated with public stigma in order to develop a positive sense of self. Participants learned to accept their MI and acknowledge the need for medication management and self-care. Increased occupational engagement with support in the social context was found to decrease the impact of internalized stigma. 


\section{CHAPTER 5}

\section{SUMMARY, CONCLUSIONS, AND RECOMMENDATIONS \\ Summary of Findings}

The nursing and psychology research presents self-stigma as having a negative impact on the quality of life (QoL) of persons with mental illness (MI). However, to the researchers' knowledge, evidence in the profession of occupational therapy regarding the effects of selfstigma on adults with MI occupational engagement, has not been pursued. The negative effects on self-esteem and self-efficacy found within other professions, and gaps in the occupational therapy (OT) literature associated with self-stigma led the purpose of the current study. A qualitative research design was utilized in order to explore the experiences of self-stigma on occupational engagement for adults with mental illness. The results of the study depicted that self-stigma is most prominent after a person receives the initial diagnosis of a MI, yet with time, and as the person learns to cope and accept their diagnosis, the degree of self-stigma is decreased, thereby increasing occupational engagement. Occupations initially impacted by selfstigma were social participation, employment, health maintenance, and self-care, however, occupational engagement increased as persons learned to accept and acknowledge the mental illness diagnosis with external support.

\section{Conclusions}

Study results present the negative influence of self-stigma on occupational engagement for adults with severe and persistent MI. The results of the study were congruent with research in other disciplines in regards to the negative effects self-stigma has on quality of life (QoL) of 
persons with MI. However, results of this study indicated the negative effects of self-stigma to be more prominent upon initially receiving a mental health diagnosis versus continually depreciating a person's sense of self throughout the lifetime. The decreased degree of self-stigma present heightens the QoL and occupational engagement for life goal attainment of persons with MI . Based on the results of the study, OTs are encouraged to provide interventions early in the course of the illness to counteract the negative impacts of self-esteem and self-efficacy associated with self-stigma on occupational engagement.

\section{Limitations and Recommendations}

Transferability is limited in this study due to the small homogenous sample and use of convenience sampling. Time restraints posed as a limitation for gathering a larger and diverse sample size. The participants were not representative of all persons diagnosed with MI, as each participant was from the same geographical region. To improve transferability of the study, the researchers recommend a sample with increased demographic variability to include persons of greater race, gender, orientations, and geographic regions. Due to varying cognitive levels, some of the participants demonstrated difficulties reflecting on personal experiences with insight. Use of a cognitive screen could result in a sample with comparable abilities across individuals.

\section{Implications}

\section{Occupational Therapy}

Based on the results of this study, implications for the profession of OT include development of a screening tool to determine the impacts of self-stigma on occupational engagement for individuals with a mental illness. Self-stigma is an important variable to address while intervening in OT (especially if the person has recently received the diagnosis) as the negative connotations associated with self-stigma directly influence the effectiveness of 
interventions. At this time, there are few if any interventions specifically tailored to address lack of occupational engagement and goal attainment associated with self-stigma in OT. Recommendations include development and implementation of OT service delivery to specifically address the initial negative effects of self-stigma.

\section{Future Research}

Several implications for future research emerged throughout the course of this study. All participants reported a history of substance abuse. Future research may explore the impact of dual diagnosis on self-stigma and occupational engagement. Additionally, exploring occupational adaptation as it continues to occur throughout the lifespan for persons with serious and chronic MI would be of interest to OTs in community-based practice. The impact of selfstigma on role identity may also improve understanding of role performance across time. Future occupational engagement studies in regards to self-stigma should include the use of a cognitive screening tool to provide for a cognitively homogeneous sample. Research findings could be used to develop a screening tool to determine the presence of self-stigma of clients receiving mental health OT services and guide intervention planning. 


\section{REFERENCES}

Angermeyer, M.C., \& Matschinger, H. (2003). The stigma of mental illness: Effects of labeling on public attitudes towards people with mental disorders. Acta Psychiatrica Scandinavia, 108, 304-309. doi: 10.1034/j.1600-0447.2003.00150.x

Angermeyer, M.C., \& Dietrich, S. (2006). Public beliefs about and attitudes towards people with mental illness: A review of population studies. Acta Psychiatrica Scandinavia, 17, 163-179. doi:10.1111/j.1600-0447.2005.00699.x

American Occupational Therapy Association. (2014). Occupational therapy practice framework: Domain and process (3rd ed.). American Journal of Occupational Therapy, 68(Suppl. 1), S1- S48. http://dx.doi.org/10.5014/ajot.2014.682006

Aronson., J., Lustina, M. J., Good, C., Keough, K., Steele, C. M., Brown, J. (1999). When white men can't do math: Necessary and sufficient factors in stereotype threat. Journal of Experimental Social Psychology, 35, 29-46. doi: 10.1006/jesp.1998.1371

Ben-Zeek, D., Young, M. A., \& Corrigan, P.W. (2010). DSM-V and the stigma of mental illness. Journal of Mental Health, 19(4), 318-327. doi: 10.3109/09638237.2010.492484

Bjorkman T., Svensson B., Lundberg B. (2007). Experiences of stigma among people with severe mental illness. Reliability, acceptability and construct validity of the Swedish versions of two stigma scales measuring devaluation/discrimination and rejection experiences. Nord Journal of Psychiatry, 61, 332-338. doi:

$10.1080 / 08039480701642961$

Boyd, J. E., Otilingam, P. G., \& DeForge, B. R. (2014). Brief version of the Internalized Stigma of Mental Illness (ISMI) scale: Psychometric properties and relationship to depression, self esteem, recovery orientation, empowerment, and perceived devaluation and 
discrimination. Psychiatric Rehabilitation Journal, 37(1), 17-23. doi:10.1037/prj0000035

Boysen, G.A., \& Vogel, D. L. (2008). Education and mental health stigma: the effects of attribution, biased assimilation, and attitude polarization. Journal of Social and Clinical Psychology, 27(5), 447-470. doi: 10.1521/jscp.2008.27.5.447

Brohan, E., Slad, M., Clement, S., \& Thornicroft, G. (2010). Experiences of mental illness stigma, prejudice, and discrimination: A review of measures. BioMedCentral Health Services Research, 10(80). doi:10.1186/1472-6963-10-80

Brohan, E., Gauci, D., Sartorius, N., \& Thornicroft, G., (2010). Self-stigma, empowerment and perceived discrimination among people with bipolar disorder or depression in 13 European countries: The GAMIAN-Europe study. Journal of Affective Disorders 129, 56-63. doi:10.1016/j.jad.2010.09.001

Brohan, E., Elgie, R., Sartorius, N., \& Thornicroft, G. (2010). Self-stigma, empowerment and perceived discrimination among people with schizophrenia in 14 European countries: The GAMIAN-Europe study. Schizophrenia Research 122, 232-238. doi:10.1016/j.schres.2010.02.1065

Brown, J. A. (2011). Talking about life after early psychosis: The impact on occupational performance. Canadian Journal of Occupational Therapy, 78, 156-163. doi: 10.2182/cjot.2011.78.3.3

Caltaux, D. (2002). Internalised stigma - A barrier to recovery. New Zealand Journal of Occupational Therapy, 49(1), 25-27. Retrieved from http://www.otnz.co.nz/public/publications/new-zealand-journal-of-occupational-therapy/ Chang, C. C., Wu, T. H., Chen, C. Y., Wang, J. D., \& Lin, C. Y. (2014). Psychometric evaluation of the internalized stigma of mental illness scale for patients with mental illnesses: Measurement invariance across time. Plos One, 9(6): e98767. doi:10.1371/journal.pone.0098767 
Clarke, J. (2004). Mad, bad, and dangerous: The media and mental illness. Mental Health Practice, 7(10), 16-19. doi: http://dx.doi.org/10.7748/mhp2004.07.7.10.16.c1815

Corrigan, P.W. (1998). The impact of stigma on severe mental illness. Cognitive and Behavioral Practice, 5, 201-222. doi: 1077-7229/98/201-22251 00/0

Corrigan, P. W. (2000). Mental health stigma as social attribution: Implications for research methods and attitude change. Clinical Psychology Science and Practice, 7, 48-67. doi: 10.1093/clipsy.7.1.48

Corrigan, P.W., Edwards, A.B., Green, A., Diwen, S.L., \& Penn, D.L. (2001). Prejudice, social distance, and familiarity with mental illness. Schizophrenia Bulletin, 27(2), 219-225. doi: 10.1093/oxfordjournals.schbul.a006868

Corrigan, P.W., River, P., Lundin, R.K., Penn, D.L., Uphoff-Wasowski, K., Campion, J., ... Kubiak, M.A. (2001). Three strategies for changing attributions about severe mental illness. Schizophrenia Bulletin, 27(2), 187-195. Retrieved from http://schizophreniabulletin.oxfordjournals.org/

Corrigan, P.W., \& Watson, A. (2002). Understanding the impact of stigma on people with mental illness. World Psychiatry, 1(1), 16-20. doi: http://www.wpanet.org/

Corrigan, P. W. (2004). How stigma interferes with mental health care. American Psychological Association, 59(7), 614-625. doi: 10.1037/0003-066X.59.7.614

Corrigan, P. W., \& Miller, F. E. (2004). Shame, blame, and contamination: A review of the impact of mental illness stigma on family members. Journal of Mental Health, 13(6), 537-548. doi: 10.1080/09638230400017004

Corrigan, P.W., Markowitz, F.E., \& Watson, A.C. (2004). Structural levels of mental illness stigma and discrimination. Schizophrenia Bulletin, 30(3), 481-49. doi: http://schizophreniabulletin.oxfordjournals.org/

Corrigan, P. W., Kerr, A., \& Knudsen, L. (2005). The stigma of mental illness: Explanatory 
models and methods for change. Applied and Preventive Psychology,11(3), 179-190. doi: 10.1016/j.appsy.2005.07.001

Corrigan, P.W., Watson, A., \& Miller, F.E. (2006). Blame, shame, and contamination: The impact of mental illness and drug dependence stigma on family members. Journal of Family Psychology, 20(2), 239-246. doi: 10.1037/0893-3200.20.2.23

Corrigan, P.W., Watson, A., \& Barr, L. (2006). The self-stigma of mental illness: Implications for self-esteem and self-efficacy. Journal of Social and Clinical Psychology, 25(9), 875-884. doi: 10.1521/jscp.2006.25.8.875

Corrigan, P.W., \& Wassel, A. (2008). Understanding and influencing the stigma of mental illness. Journal of Psychosocial Nursing and Mental Health Services, 46, 42-48. doi:http://dx.doi.org.ezproxy.undmedlibrary.org/10.3928/02793695-20080101-04

Corrigan, P., Larson, J., \& Rusch, N. (2009). Self-stigma and the "why try" effect: impact on life goals and evidence-based practices. World Psychiatry, 8(2),75-81. Retrieved from http://www.wpanet.org/

Corrigan, P. W., Rafacz, J., \& Rusch Nicolas. (2011). Examining a progressive model of self-stigma and its impact on people with serious mental illness. Psychiatry Research, 189(3), 339-343. doi: 10.1016/j.psychres.2011.05.024

Corrigan, P.W. (2011). Strategic stigma change (SSC): Five principles for social marketing campaigns to reduce stigma. Psychiatric Services, 62(8), 824-826. doi:

\subsection{6/appi.ps.62.8.824}

Corrigan, P.W., Powell, K.J., \& Rusch N. (2012). How does stigma affect work in people with serious mental illness? Psychiatric Rehabilitation Journal, 35(5), 381-384. doi: $10.1037 / \mathrm{h} 0094497$

Corrigan, P. W., \& Rao, D. (2012). On the self-stigma of mental illness: Stages, disclosure, and strategies for change. Canadian Journal Of Psychiatry, 57(8), 464-469. Retrieved 
from http://publications.cpa-apc.org/browse/sections/0

Corrigan, P.W., Michaels, P.J., Vega, E., Gause, M., Watson, A.C., \& Rusch, N. (2012). Self-stigma of mental illness scale-short form: Reliability and validity, Psychiatry Research, 199, 65-69. doi: http://dx.doi.org/10.1016/j.psychres.2012.04.009

Corrigan, P. W., Kosyluk, K. A., \& Rüsch, N. (2013). Reducing self-stigma by coming out proud. American Journal of Public Health, 103, 794- 800. doi:http://dx.doi.org/10.2105/AJPH.2012.301037

Corrigan, P. W., \& Penn, D. L. (2015). Lessons from social psychology on discrediting psychiatric stigma. Stigma and Health, 1(S), 2-17. doi: http://dx.doi.org/10.1037/2376-6972.1.S.2

Corrigan, P. W., Gause, M., Michaels, P. J., Buchholtz, B. A., \& Larson, J. E. (2015). The California assessment of stigma change: A short battery to measure improvements in the public stigma of mental illness. Community Mental Health Journal, 51, 635-640. doi: $10.1007 / \mathrm{s} 10597-014-9797-5$

Crocker, J., Major, B., \& Steele, C. (1998). Social stigma. In D.T. Gilbert, S. Fiske, \& G. Lindzey (Eds.), The handbook of social psychology (Vol. 2, 4th ed, pp. 504-553). New York, NY: McGraw-Hill.

Dunn, W., Brown, C., \& McGuigan, A. (1994). The ecology of human performance: A framework for considering the effect of context. American Journal of Occupational Therapy, 48(7), 595-607. doi: 10.5014/ajot.48.7.595

Ehrlich-Ben Or, S., Hasson-Ohayon, I., Feingold, D., Vahab, K., Amiaz, R., Weiser, M., Lysaker, P. (2013). Meaning in life, insight, and self-stigma among people with severe mental illness. Comprehensive Psychiatry, 54, 195-200. doi:http://dx.doi.org/10.1016/j.comppsych.2012.07.011

Fung, K. M. T., Tsang, H. W. H., \& Cheung, W. M. (2011). Randomized controlled trial of the 
self-stigma reduction program among individuals with schizophrenia. Psychiatry Research, 189, 208-214. doi:10.1016/j.psychres.2011.02.013

Goffman, E. (1963). Stigma: Notes on the management of spoiled identity. Englewood Cliffs, NJ: Prentice Hall.

Halpern, E. S. (1983). Auditing naturalistic inquiries: The development and application of a model. Unpublished doctoral dissertation, Indiana University.

Hinshaw, S. P., \& Stier, A. (2008). Stigma as related to mental disorders. Annual Review of Clinical Psychology, 4, 367-393. doi: 10.1146/annurev.clinpsy.4.022007.141245

Holmes E. P., Corrigan P. W., Williams P., Canar, J., Kubiak, M.A. (1999). Changing attitudes about schizophrenia. Schizophrenia Bulletin, 25(3), 447-456. doi: http://schizophreniabulletin.oxfordjournals.org/

Ilic, M., Reinecke, J., Bohner, G., Rottgers, H-O., Beblo, T., Driessen, M.,... Corrigan, P.W. (2011). Protecting self-esteem from stigma: A test of different strategies for coping with the stigma of mental illness. International Journal of Social Psychology, 53(3), 246-257. doi: $10.1177 / 0020764010392058$

Knight, M.T.D., Wykes, T., \& Hayward, P. (2003). 'People don't understand': An investigation of stigma in schizophrenia using interpretative phenomenological analysis (IPA). Journal of Mental Health, 12(3), 209-222. doi: 10.1080/0963823031000118203

Kroska, A., \& Harkness, S. K. (2006). Stigma sentiments and self-meanings: Exploring the modified labeling theory of mental illness. American Sociological Association, 69(4), 325-348. Retreived from: http://www.jstor.org/stable/20141754

Larson, J.E., \& Corrigan, P.W. (2008). The stigma of families with mental illness. Academic Society, 32(2), 87-91. doi: 10.1176/appi.ap.32.2.87

Lincoln, Y. S., \& Gruba, E. G. (1985). Naturalistic Inquiry. SAGE Productions.

Link, B. G., Cullen, F. T., Struening, E., Shrout, P. E., \& Dohrenwend, B. P. (1989). A modified 
labeling theory approach to mental disorders: An empirical assessment. American Sociological Association, 54(3), 400-423. Retrieved from: http://www.jstor.org/stable/2095613

Link, B. G., \& Phelan, J. C. (2001). Conceptualizing stigma. Annual Review of Sociology, 27, 363-385. Retrieved from: http://search.proquest.com/docview/199727731?accountid=40810

Livingston, J.D., \& Boyd, J. E. (2010). Correlates and consequences of internalized stigma for people living with mental illness: A systematic review and meta-analysis. Social Science and Medicine, 70, 2150-2161. doi: :10.1016/j.socscimed.2010.09.030

Lloyd, C., Sullivan, D., \& Williams, P.E. (2005). Perceptions of social stigma and its effect on interpersonal relationships of young males who experience psychotic disorder. Australian Journal of Occupational Therapy, 52, 243-250. doi: 10.1111/j.1440-1630.2005.00504.x

Lucksted, A., Drapalski, A., Calmes, C., Forbes, C., Deforge, B., \& Boyd, J. (2011). Ending self-stigma: pilot evaluation of a new intervention to reduce internalized stigma among people with mental illnesses. Psychiatric Rehabilitation Journal, 35(1), 51-54. doi:10.2975/35.1.2011.51.54

Madison, D. S. (2005). Critical ethnography: Method, ethics, and performance. Thousand Oaks, California: Sage Publications.

Major, B., \& O'Brien, L. T. (2005). The social psychology of stigma. Annual Review of Psychology, 56, 393-421. doi: 10.1146/annurev.psych.56.091103.070137

Markowitz, F.E. (1998). The effects of stigma on psychological well-being and satisfaction of persons with mental illness. Journal of Health and Social Behavior, 39(4), 335-347. Retrieved from http://hsb.sagepub.com/

Marshall, C. \& Rossman, G. (1999). Designing qualitative research (3rd ed.). Thousand Oaks, California: Sage Publications. 
Martin, J. K., Pescosolido, B. A., Olafsdottir, S., \& McLeod, J. D.(2007). The construction of fear: Americans' preferences for social distance from children and adolescents with mental health problems. Journal of Health and Social Behavior, 48(1), 50-67. Retrieved from http://hsb.sagepub.com/

McCay, E., Beanlands, H., Zipursky, R., Roy, P., Leszcz, M., Landeen, J., . . Chan, E. (2007). A randomised controlled trial of a group intervention to reduce engulfment and self-stigmatisation in first episode schizophrenia. Advances in Mental Health, 6 , 212-220. doi:http://dx.doi.org/ 10.5172/jamh.6.3.212

Michlack, E., Livingston, J. D., Hole, R., Suto, M., Hale, S., \& Haddock, C. (2011). 'It’s something that I manage but it is not who I am': Reflections on internalized stigma in individual with bipolar disorder. Chronic Illness, 7(3), 209-224.

doi: $10.1177 / 1742395310395959$

Mittal, D., Sullivan, G., Chekuri, L., Allee, E., Corrigan, P. W. (2012). Empirical studies of self-stigma reduction strategies: A critical review of literature. Psychiatric Services 63, 974-981. doi: 10.1176/appi. ps.201100459

Moustakas, C. (1994). Phenomenological research methods. Thousand Oaks, CA: SAGE Publications, Inc.

National Alliance on Mental Illness (2013, March). Mental illness: Facts and numbers. Arlington, VA: Ken Duckworth.

Patton, M. Q. (1990). Qualitative Research and Evaluation Methods (2nd Ed.). Newbury Park California: Sage.

Peluso, E. d. T. P., \& Blay, S. L. (2009). Public stigma in relation to people with depression. Journal of Affective Disorders, 115, 201-206. doi: 10.1016/j.jad.2008.08.013

Perez-Garin, D., Molero, F., \& Bos, A. (2015). Internalized mental illness stigma and subjective well-being: The mediating role of psychological well-being. Psychiatry Research, 228(3), 
325-331. doi:http://dx.doi.org/10.1016/j.psychres.2015.06.029

Perlick, D.A., Rosenheck, R.A., Clarkin, J.F., Sirey, J.A., Salahi, J., Struening, E.L., \& Link, B.G. (2001). Adverse effects of perceived stigma on social adaptation of persons diagnosed with bipolar affective disorder. Psychiatric Services, 52(12), 1627-1632.

Pescosolido, B. A., Medina, T. R., Martin, J. K., \& Long, J. S. (2013). The "backbone” of stigma: identifying the global core of public prejudice associated with mental illness. American Journal of Public Health, 10(3), 853-860. doi: 10.2105/AJPH.2012.301147

Quinn, D. M., Williams, M. K., \& Weisz, B. M. (2015). From discrimination to internalized stigma: The mediating roles of anticipated discrimination and anticipated stigma. American Psychological Association, 38(2), 103-108. doi: http://dx.doi.org/10.1037/prj0000136

Raphael-Greenfield, E. I. \& Gutman, S. (2015) Understanding the lived experience of formerly homeless adults as they transition to supportive housing. Occupational Therapy in Mental Health, 31, 35-49. doi:10.1080/0164212X.2014.1001011

Ritsher, J. B., Otilingam, P. G., \& Grajales, M. (2003). Internalized stigma of mental illness: Psychometric properties of a new measure. Retrieved from eScholarship University of California: https://escholarship.org/uc/item/3xp4748j

Ritsher, J. B., \& Phelan, J. C. (2004). Internalized stigma predicts erosion of morale among psychiatric outpatients. Psychiatry Research, 129(3), 257-265. Retrieved from eScholarship University of Californa: http://escholarship.org/uc/item/58q4993s

Rosenfield, S. (1997). Labeling mental illness: The effects of received services and perceived stigma on life satisfaction. American Sociological Review, 62(4), 660-672.

Rusch, N., Corrigan, P.W., Powell, K., Rajah, A., Olschewski, M., Wilkness, S., \& Batia, K. (2009). A stress coping model of mental illness stigma: II. emotional stress responses, coping behavior and outcome. Schizophrenia Research, 110, 65-71. doi: 
10.1016/j.schres.2009.01.005

Rusch, N., Corrigan, P. W., Todd, A. R., \& Bodenhausen, G. V. (2010). Implicit self stigma in people with mental illness. Journal of Nervous and Mental Disease, 198(2), 150-153. doi: 10.1097/NMD.0b013e3181cc43b5

Russinova, A., Rogers, E. S., Gagne, C., Bloch, P., Drake, K. M., \& Mueser, K. T. (2014). A randomized controlled trial of a peer-run antistigma photovoice intervention. Psychiatric Services, 65, 242-246. doi:http://dx.doi.org/10.1176/appi.ps.201200572

Shimotsu, S., Horikawa, N., Emura, R., Ishikawa, S-I., Nagao, A., Ogata, A., ...Hosomi, J. (2014). Effectiveness of group cognitive-behavioral therapy in reducing self-stigma in japanese psychiatric patients. Asian Journal of Psychiatry, 10, 39-44. doi: http://dx.doi.org/10.1016/j.ajp.2014.02.006

Simons, M. (2011.). The role of the researcher (Doctoral dissertation). Retrieved from http://dissertationrecipes.com/wp-content/uploads/2011/04/Role-of-the-Researcher.pdf

Steele, C. M., Spencer, S. J., \& Aronson, J. (2002). Contending with group image: The psychology of stereotype and social identity threat. Advances in Experimental Social Psychology, 34, 379-440. Retrieved from:

http://disjointedthinking.jeffhughes.ca/wp-content/uploads/2011/07/Steele-Spencer-Aron son-2002.-Contending-with-group-image.pdf

Switaj, P., Grygiel, P., Anczewska, M., \& Wciorka, J. (2014). Loneliness mediates the relationship between internalized stigma and depression among patients with psychotic disorders. International Journal of Social Psychology, 60(8), 733-740. doi: $10.1177 / 0020764013513442$

Teplin, L.A. (1984). Criminalizing mental disorder: The comparative arrest rate of the mentally ill. American Psychologist, 39(7), 794-803. doi: http://dx.doi.org/10.1037/0003-066X

Teplin, L.A. (1985). The criminality of the mentally ill: A dangerous misconception. American 
Journal of Psychiatry, 142(5), 593-599.

Thornicroft, G., Rose, D., Kassam, A., \& Sartorius, N. (2007). Stigma: Ignorance, prejudice, or discrimination? British Journal of Psychiatry, 190, 192-193. doi: 10 .11 92 / bjp . b p .1 06.025791

Vogel, D. L., Wade, N. G., \& Haake, S. (2006). Measuring the self-stigma associated with seeking psychological help. American Psychological Association, 53(3), 325-337. doi:10.1037/0022-0167.53.3.325

Vogel, D.L., Shechtman, Z., \& Wade, N.G. (2010). The role of public stigma and self-stigma in predicting attitudes toward group counseling. The Counseling Psychologist, 38(7), 904-922. doi: 10.1177/0011000010368297

Vogel, D. L., Armstrong, P. I., Tsai, P. C., Wade, N. G., Hammer, J. H., Holtham, E...Topkaya, N. (2013). Cross cultural validity of the self-stigma of seeking self-help (SSOSH) scale: Examination across six nations. Journal of Counseling Psychology, 60(2), 303-310. doi: $10.1037 / \mathrm{a} 0032055$

Vogel, D.L., Bitman, R.L., Hammer, J.H., \& Wade, N.G. (2013). Is stigma internalized? The longitudinal impact of public stigma on self-stigma. Journal of Counseling Psychology, 60(2), 311-316. doi: 10.1037/a0031889

Wahl, O.F., \& Harman, C.R. (1989). Family views of stigma. Schizophrenia Bulletin, 15(1), 131-139. doi:10.1093/schbul/15.1.131

Watson, A.C., Corrigan, P.W., \& Ottati, V. (2004). Police officers' attitudes toward and decisions about persons with mental illness. Psychiatric Services, 55(1), 49-53.

Watson, A. C., \& Corrigan, P. W. (2005). Challenging public stigma: A targeted approach. In P.W. Corrigan, (Ed.), On the stigma of mental illness: Practical strategies for research and social change.(pp. 281-295). Washington, DC, US: American Psychological Association, xv, 343 
World Health Organization (2001). World health report: Mental disorders affect one in four people. Retrieved from http://www.who.int/whr/2001/media_centre/press_release/en/

Xu, M. A. \& Storr, G. B. (2012). Learning the concept of researcher as instrument in qualitative research. Qualitative Report, 17(42), 1-18. Retrieved from http://nsuworks.nova.edu/cgi/viewcontent.cgi?article=1768\&context=tqr

Yanos, P.T., Roe, D., Markus, K., \& Lysaker, P.H. (2008). Pathways between internalized stigma and outcomes related to recovery in schizophrenia spectrum disorders. Psychiatric Services, 59(12), 1437-1443. Retrieved from http://search.proquest.com.ezproxy.undmedlibrary.org/docview/213081602?accountid=4 0810

Yanos, P.T., Roe, D., \& Lysaker, P.H. (2011). Narrative enhancement and cognitive therapy: A new group -based treatment for internalized stigma among persons with severe mental illness. International Journal of Group Psychotherapy, 61(4), 576-595. doi: 10.1521/ijgp.2011.61.4.576

Yanos, P. T., Lucksted, A., Drapalski, A. L., Roe, D., \& Lysaker, P. (2015). Interventions targeting mental health stigma: A review and comparison. Psychiatric Rehabilitation Journal, 38(2), 171-178. doi: http://dx.doi.org/10.1037/prj0000100 
APPENDICES 
Appendix A

Recruitment Flier 


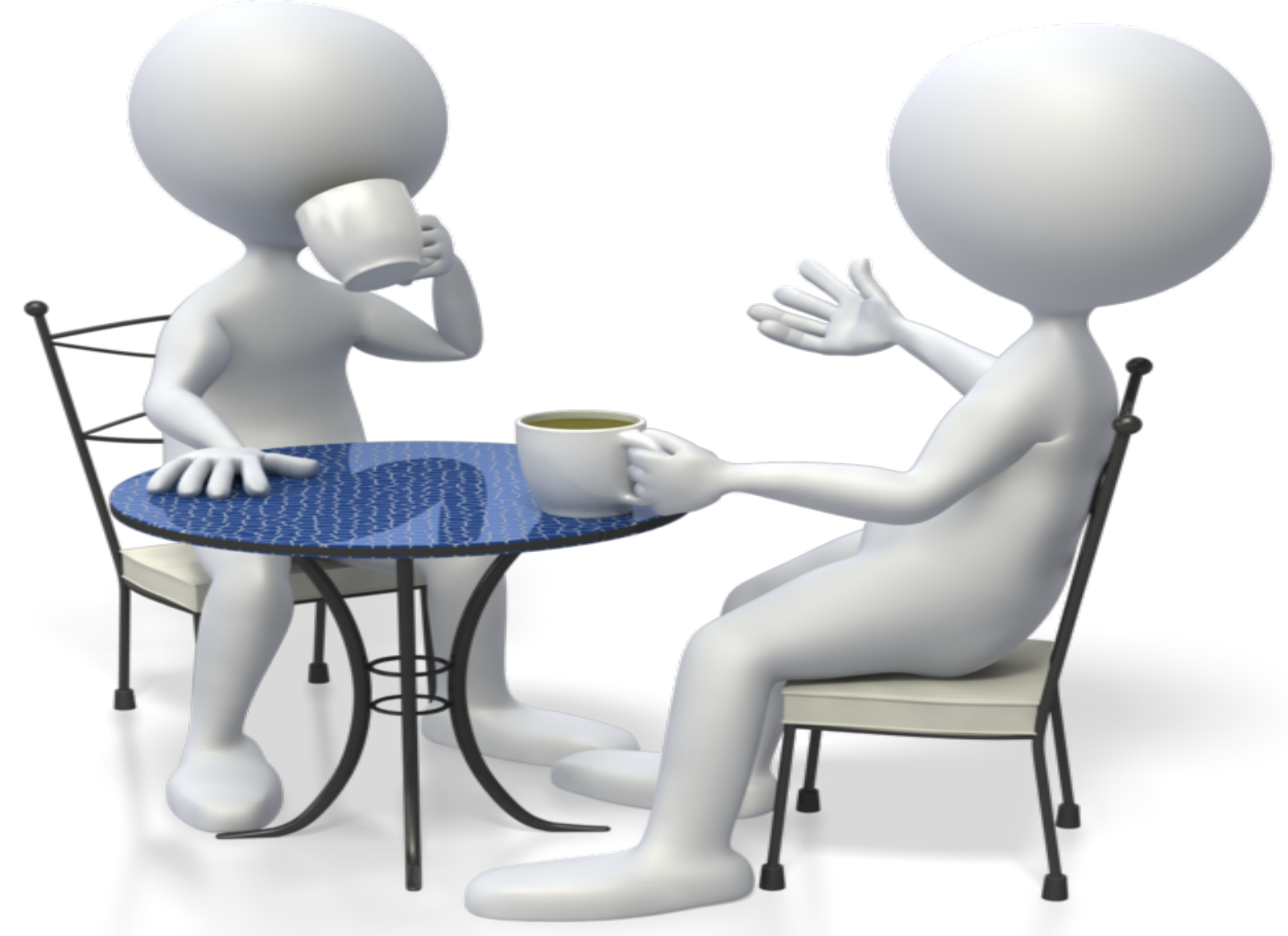

You're invited to participate in research! Hugo's giftcard provided

In your home or at Prairie Harvest Mental Health

Research involves two $1 / 2$ hour interviews at a time that works for you. Participants will receive a gift card to Hugo's

Contact Taylor (701-330-5386) or Alyssa (320-250-8449) for more information 
Appendix B

Prairie Harvest Mental Health Consent Form 


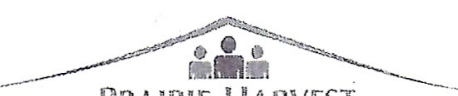

PRAIRIE HARVEST

MENTAL HEALTH

930 North Third Street * Grand Forks, ND 58203-2408

To Whom It May Concern,

Prairie Harvest Mental Health has agreed to work with Taylor LaVoi and her classmate regarding an Independent Study. This study will be conducted under the guidance of Dr. Sonia Zimmerman at the University of North Dakota, Occupational Therapy Department. The attached Confidentiality Agreement will need to be signed and returned to Prairie Harvest Mental Health.

Prairie Harvest Mental Health is willing to allow Taylor and her classmate to interview current clients of Prairie Harvest Mental Health. The process will include recruiting 6 or more clients, having Releases of Information signed, interviewing clients approximately twice for half hour to an hour at a time and providing incentives for such interviews. Taylor and her classmate may interview clients in their homes or at a designated place at Prairie Harvest Mental Health.

If clients need additional counseling or assistance to process their emotions they will be referred to their Prairie Harvest Mental Health Case Assistant.

Taylor and her classmate have agreed to present and provided a copy of the study to Prairie Harvest Mental Health staff. Date of the presentation is to be determined.

Sincerely,

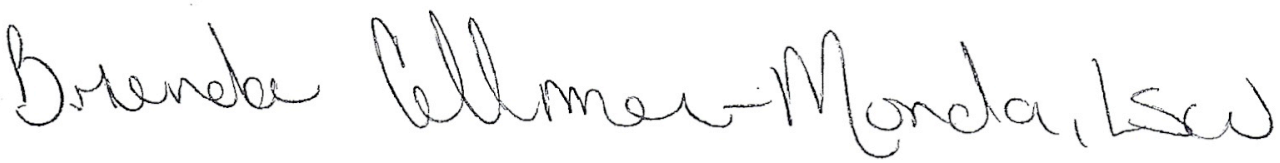

Brenda Cellmer-Monda, LSW Supported Residential Facilitator

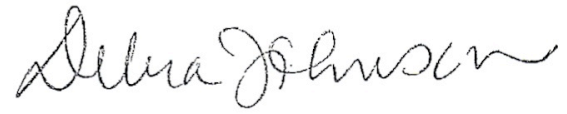

Debra Johnson, Chief Executive Officer 
Appendix C

Researchers' Confidentiality Agreement 


\section{CONFIDENTPALITY AGREEMENT}

Given the sensitive and highly personal nature of much of the client related work performed by Prairie Harvest Mental Health/The Home Place Corporation, it is expected that all employees and volunteers who have access to client information will consistently and uniformly maintain the privacy and confidentiality of this information. The same degree of confidentiality is to be maintained for management and personinel records.

Employees and volunteers of Prairie Harvest Mental Health/The Home Place Corporation agree to hold in strict confidence any information of a sensitive nature as stated in the above paragraph.

I have read and will adhere to the confidentiality agreement.

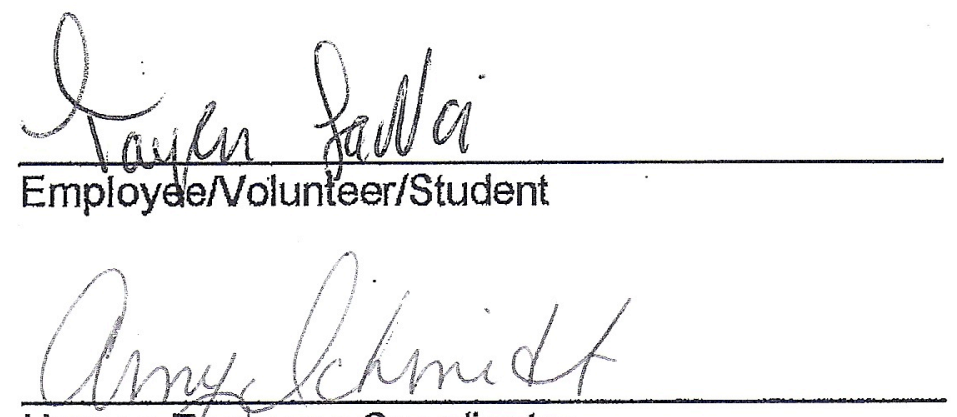

Human/Resource Coordinator
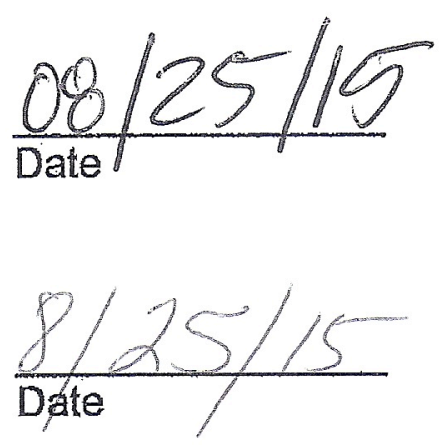


\section{CONFIDENTIALITY AGREEMENT}

Given the sensitive and highly personal nature of much of the client related work performed by Prairie Harvest Mental Health/The Home Place Corporation, it is expected that all employees and volunteers who have access to client information will consistently and uniformly maintain the privacy and confidentiality of this information. The same degree of confidentiality is to be maintained for management and personnel records.

Employees and volunteers of Prairie Harvest Mental Health/The Home Place Corporation agree to hold in strict confidence any information of a sensitive nature as stated in the above paragraph.

I have read and will adhere to the confidentiality agreement.
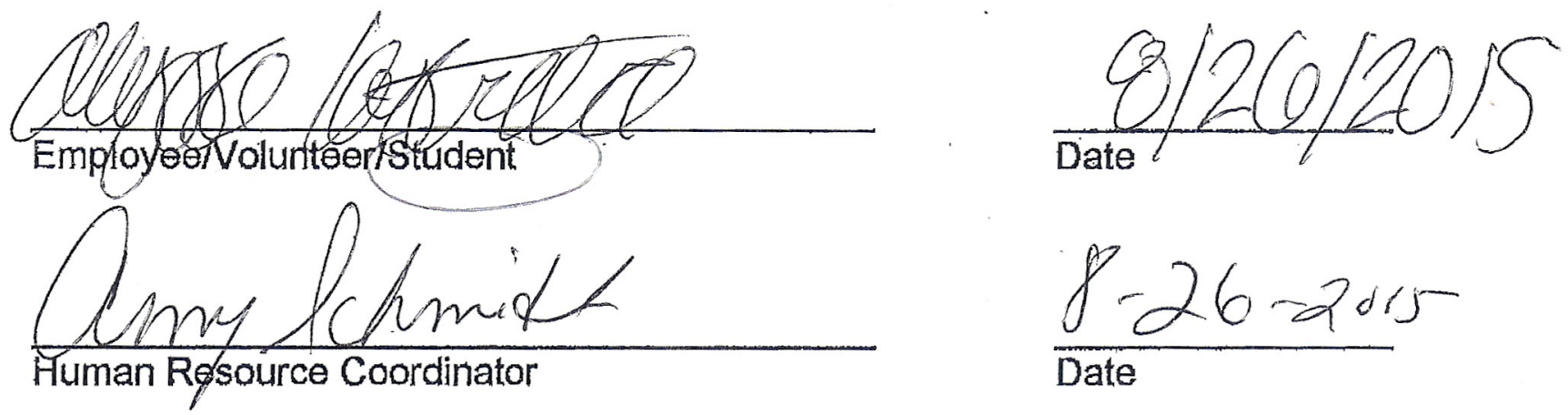
Appendix D

Informed Consent 


\section{THE UNIVERSITY OF NORTH DAKOTA CONSENT TO PARTICIPATE IN RESEARCH}

TITLE:

PROJECT DIRECTOR:

PHONE \#

DEPARTMENT:
The Effects of Self-Stigma on Occupational Engagement for Adults with Mental Illness

Alyssa Kostreba \& Taylor LaVoi, both Masters of Occupational Therapy Students; Dr. Sonia Zimmerman, Ph.D, OTR/L FAOTA

701-777-2209

Occupational Therapy

\section{STATEMENT OF RESEARCH}

A person who is to participate in the research must give his or her informed consent to such participation. This consent must be based on an understanding of the nature and risks of the research. This document provides information that is important for this understanding. Research projects include only subjects who choose to take part. Please take your time in making your decision as to whether to participate. If you have questions at any time, please ask.

\section{WHAT IS THE PURPOSE OF THIS STUDY?}

You are invited to be in a research study about the possible effects of self-stigma on a person's daily life because you are affiliated with Prairie Harvest Mental Health and fit the inclusion criteria for our study, which consists of being over the age of 21 and having a mental health diagnosis.

The purpose of this research study is to understand how self-stigma affects a person's willingness to pursue goals within one's life. Self-stigma can be described as personally believing the negative stereotypes associated with persons who have mental illness. These goals can often consist of daily activities such as work, education, and social relationships. Our expectation is that self-stigma will be reported as a barrier to pursuing life goals. Based upon the results of this study, occupational therapists can determine and implement appropriate intervention to resolve the negative influences of self-stigma on a person's daily life.

\section{HOW MANY PEOPLE WILL PARTICIPATE?}

Approximately 4-6 people will take part in this study at the University of North Dakota.

\section{HOW LONG WILL I BE IN THIS STUDY?}

\begin{tabular}{|c|c|c|c|}
\hline Approval Date: & AUG & 4 & 2015 \\
\hline Expiration Date: & AUG & 3 & 2016 \\
\hline
\end{tabular}


Your participation in the study will consist of two interviews. Dependent upon your comfort levels, interviews may be conducted in your home or at Prairie Harvest Mental Health. Each visit will take about 30-45 minutes

\section{WHAT WILL HAPPEN DURING THIS STUDY?}

For this study, you will be completing two interviews with one of the researchers. Each interview will consist of questions that pertain to the possible impact of self-stigma on your daily life activities. You are free to withdraw from this study at any time without any negative consequences.

\section{WHAT ARE THE RISKS OF THE STUDY?}

There may be some minimal risks from participating in this study. Questions that may trigger emotional responses can be discounted at any time. We will refer you to your case manager if you would like any additional resources following the interview.

\section{WHAT ARE THE BENEFITS OF THIS STUDY?}

You may benefit personally from being in this study by gaining knowledge of what self-stigma is and how self-stigma may affect you. We hope that, in the future, other people might benefit from this study because you can help future occupational therapists develop treatment to address selfstigma.

\section{ALTERNATIVES TO PARTICIPATING IN THIS STUDY}

The alternative to being in this study is to not participate in the study.

\section{WILL IT COST ME ANYTHING TO BE IN THIS STUDY?}

You will not have any costs for being in this research study.

\section{WILL I BE PAID FOR PARTICIPATING?}

You will receive a gift card valued at $\$ 5.00$ for participating in this research study. The gift card will be distributed upon completion of the second interview.

\section{WHO IS FUNDING THE STUDY?}

The University of North Dakota and the research team are receiving no payments from other agencies, organizations, or companies to conduct this research study.

\section{CONFIDENTIALITY}

Approval Date: $\begin{array}{llll} & \text { AUG } & 4 & 2015 \\ \text { Expiration Date: } & \text { AUG } & 3 & 2016 \\ \text { University of North Dakota IRB }\end{array}$


The records of this study will be kept private to the extent permitted by law. In any report about this study that might be published, you will not be identified. Your study record may be reviewed by Government agencies, the UND Research Development and Compliance office, and the University of North Dakota Institutional Review Board.

Any information that is obtained in this study and that can be identified with you will remain confidential and will be disclosed only with your permission or as required by law. You should know, however, that there are some circumstances in which we may have to show your information to other people. For example the law may require us to show your information to a court or to tell authorities if we believe you have abused a child, or you pose a danger to yourself or someone else. Confidentiality will be maintained by means of utilizing pseudonyms in our final study. Information will be stored in a secure location.

If we write a report or article about this study, we will describe the study results in a summarized manner so that you cannot be identified.

Each of the interviews will be digitally-recorded, then transcribed verbatim by the interviewer. Digital-recordings will be erased immediately upon transcription. Transcriptions will be stored in a locked file cabinet on an external drive in the research advisor's office. You may request to review the transcriptions and signed informed consent for up to three years post-study.

\section{IS THIS STUDY VOLUNTARY?}

Your participation is voluntary. You may choose not to participate or you may discontinue your participation at any time without penalty or loss of benefits to which you are otherwise entitled. Your decision whether or not to participate will not affect your current or future relations with the University of North Dakota.

If you decide to leave the study early, we ask that you inform the interviewers of your decision. You will not receive the gift card if both interviews are not completed in their entirety.

\section{CONTACTS AND QUESTIONS?}

The researchers conducting this study are Alyssa A. Kostreba, MOTS; Taylor E. LaVoi, MOTS; \& Dr. Sonia Zimmerman, Ph.D, OTR/L, FAOTA. You may ask any questions that you have at this time. If you later have questions, concerns, or complaints about the research please contact Alyssa A. Kostreba, MOTS; Taylor E. LaVoi, MOTS; or Dr. Sonia Zimmerman, Ph.D, OTR/L, FAOTA at 320-250-8449, 701-330-5386, or 701-777-2209.

Approval Date:
Expiration Date:
University of North Dakota IRB


If you have questions regarding your rights as a research subject, you may contact The University of North Dakota Institutional Review Board at (701) 777-4279.

- You may also call this number about any problems, complaints, or concerns you have about this research study.

- You may also call this number if you cannot reach research staff, or you wish to talk with someone who is independent of the research team.

- General information about being a research subject can be found by clicking "Information for Research Participants" on the web site: http://und.edu/research/resources/human-subjects/research-participants.cfm

I give consent to be audiotaped during this study.

Please initial: $\quad$ Yes $\quad$ No

I give consent for my quotes to be used in the research; however I will not be identified.

Please initial: _ Yes _ No

Your signature indicates that this research study has been explained to you, that your questions have been answered, and that you agree to take part in this study. You will receive a copy of this form.

Subjects Name:

Signature of Subject

Date

I have discussed the above points with the subject or, where appropriate, with the subject's legally authorized representative.

Signature of Person Who Obtained Consent

Date

Approval Date:

Expiration Date: AUG 12015

University of North Dakota IRB

Date: Subject Initials: 
Appendix E

IRB Approval 


\begin{tabular}{|ll|}
\hline Principal Investigator: & $\begin{array}{l}\text { Alyssa Kostreba and Taylor LaVoi } \\
\text { The Effects of Self-Stigma on Occupational Engagement for Adults } \\
\text { with Mental Illness }\end{array}$ \\
$\begin{array}{l}\text { IRB Project Title: } \\
\text { IRB-201508-028 }\end{array}$ \\
$\begin{array}{l}\text { Project Review Level: } \\
\begin{array}{l}\text { Date of IRB Approval: } \\
\text { Expiration Date of This }\end{array}\end{array}$ & $08 / 04 / 2015$ \\
$\begin{array}{l}\text { Approval: } \\
\text { Consent Form Approval } \\
\text { Date: }\end{array}$ & $08 / 03 / 2016$ \\
\hline
\end{tabular}

The application form and all included documentation for the above-referenced project have been reviewed and approved via the procedures of the University of North Dakota Institutional Review Board.

Attached is your original consent form that has been stamped with the UND IRB approval and expiration dates. Please maintain this original on file. You must use this original, stamped consent form to make copies for participant enrollment. No other consent form should be used. It must be signed by each participant prior to initiation of any research procedures. In addition, each participant must be given a copy of the consent form.

Prior to implementation, submit any changes to or departures from the protocol or consent form to the IRB for approval. No changes to approved research may take place without prior IRB approval.

You have approval for this project through the above-listed expiration date. When this research is completed, please submit a termination form to the IRB. If the research will last longer than one year, an annual review and progress report must be submitted to the IRB prior to the submission deadline to ensure adequate time for IRB review.

The forms to assist you in filing your project termination, annual review and progress report, adverse event/unanticipated problem, protocol change, etc. may be accessed on the IRB website: http://und.edu/research/resources/human-subjects/

Sincerely,
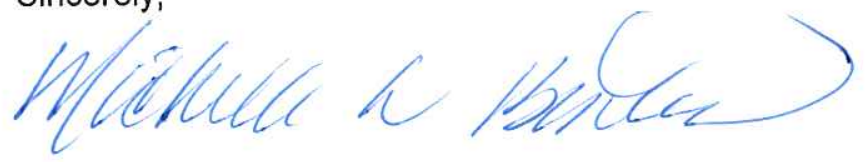

Michelle L. Bowles, M.P.A., CIP IRB Coordinator

MLB/jle

\section{Enclosures}

Cc: Sonia S. Zimmerman, Ph.D. 
Appendix F

Interview Questions 


\section{Interview Questions}

\section{Interview One}

Thank you for agreeing to this interview. I appreciate your taking time out of your day to share with me. The purpose of my study is to evaluate the effects of self-stigma on a person's daily life engagement. Today we're going to talk about your experiences with the general public's response to you as someone with a mental illness diagnosis.

You do not need to answer questions you are uncomfortable answering. Please ask for clarification at any moment in time. Do you have any questions at this time?

1. Tell me a little about yourself

a. .....the kinds of activities you're currently engaged in?

b. living arrangement?

c. employment?

d. relationships?

2. Now I'd like you to think back in time.......How many years has it been since your were first diagnosed with a mental illness?

a. if you don't mind sharing with me, what is your diagnosis?

3. Tell me a little about what your life was like at the time you were first diagnosed?

a. what kinds of things were doing? (school, employment, relationships)

4. Thinking about that time in your life up to the present, have you ever noticed that people treat you differently since you received your diagnosis?
a. (if no, have you ever seen this happen to anyone you know?)
b. if so, how do you perceive that you were treated differently?
c. can you give some examples? (feelings experienced in those situations)

5. What I hear you describing is what is called stigma, where an individual or individuals feel like they are being treated or viewed differently because of their mental illness. Did you have a moment/time when you first realized this was happening to you?

a. Describe that moment/time ......

6. How has this form of stigma influenced the way you view yourself?

7. Those are all of the questions I have prepared for today. Would you like to discuss anything else before we conclude our time together? 
a. again, thank you so much for agreeing to participate in our research project. Your thoughts and ideas are certainly a valued part of this process and your comments are appreciated.

Now, let's talk about a time when we can meet again, preferably in the next week to 10 days. 


\section{Interview Two}

Thank you for coming to meet with me today. I really appreciate your willingness to be a part of this project. Is there anything you perhaps thought about since we last met and would like share today before we start with the second interview?

When we last met, we talked a good bit about stigma and how individuals experience reactions to them once diagnosed with a mental illness.

Today we will discuss self-stigma. Self-stigma occurs when individuals with mental illness begin to agree with the often negative stereotypes that others in the general public have toward persons with mental illness and begin to feel as if they are not equal to others in society. I am especially interested in how the individual begins to change personal goals and engagement in life activities.

You do not need to answer questions you are uncomfortable answering. Please ask for clarification at any time. Do you have any questions before we begin?

1. Tell me about how you perceive yourself today.

a. What are the things that you like about yourself? (things you can do well, things you enjoy about who you are)

b. what changes would you like see?

2. How has your perception of yourself influenced your ability to seek healthcare services?
a. care for yourself?
b. trust others to establish relationships?
c. secure employment or attend school?
d. feel secure in your living arrangement?

3. Tell me how you view yourself compared to others who do not have a mental illness?
a. insights gained?
b. feelings of inequality?

4. Describe your life goals that you are currently working to achieve.
a. are they different than what you saw as life goals prior to your diagnosis?
b. how did you come to realize that you needed to change your goals?

5. Tell me about your perception of your ability to achieve your goals. 
a. Do you feel your perception of your ability to achieve life goals has changed as a result of your diagnosed mental illness?

b. if so, in what way (s)?

c. if no, move to next question...

6. "Why Try" statements have been reported as occurring for individuals that believe they are going to fail due to their diagnosis of a mental illness.

a. have you ever experienced this way of thinking?

b. what was going on in your life at that time?

c. how does a "why try" attitude affect your approach to life activities?

d. if no, have you ever seen this happen to anyone you know?

7. This concludes our interview today. Again, thank you for your willingness to participate in our research project; I greatly appreciate your time and your input.

a. Is there anything else you would like to share before we conclude our interview? 
Appendix G

Audit Trail 
Audit Trail

\begin{tabular}{|c|c|c|}
\hline $\begin{array}{l}\text { Audit Trail } \\
\text { Classification }\end{array}$ & File Types & Evidence \\
\hline Raw Data & $\begin{array}{l}\text { A. Electronically Recorded Materials } \\
\text { a. Digital Recordings and Transcripts }\end{array}$ & $\begin{array}{l}\text { A. Audio Recordings } \\
\text { B. Typed Transcripts } \\
\text { a. Researcher } 1 \\
\text { b. Researcher } 2\end{array}$ \\
\hline $\begin{array}{l}\text { Data Reduction } \\
\text { and Analysis }\end{array}$ & $\begin{array}{l}\text { A. Summaries } \\
\text { a. In vivo Codes } \\
\text { b. Categories }\end{array}$ & $\begin{array}{l}\text { A. Researcher's Transcript Summaries } \\
\text { a. Researcher } 1 \\
\text { b. Researcher } 2 \\
\text { B. Codes } \\
\text { C. Categories } \\
\text { a. Table } 4.1\end{array}$ \\
\hline $\begin{array}{l}\text { Data } \\
\text { Reconstruction } \\
\text { and Synthesis }\end{array}$ & $\begin{array}{l}\text { A. Categorical Structure } \\
\text { a. Themes } \\
\text { B. Findings and Conclusions } \\
\text { a. Textural and Structural Description } \\
\text { b. Final Assertion } \\
\text { C. Final Report } \\
\text { a. Connections to Existing Literature } \\
\text { b. Integration of Concepts, Relationships, and } \\
\text { Interpretations }\end{array}$ & $\begin{array}{l}\text { A. Hierarchies of In vivo Codes, } \\
\text { Horizontalization Statements, and } \\
\text { Categories } \\
\quad \text { a. Table } 4.2 \\
\text { B. Explanation of Concepts }\end{array}$ \\
\hline Process Notes & $\begin{array}{l}\text { A. Methodological Notes } \\
\text { a. Procedures } \\
\text { b. Decisions } \\
\text { c. Strategies } \\
\text { d. Rationale } \\
\text { B. Trustworthiness Notes } \\
\text { a. Credibility }\end{array}$ & $\begin{array}{l}\text { A. Refer to Chapter } 3 \\
\text { B. Formulated Audit Trail }\end{array}$ \\
\hline
\end{tabular}




\begin{tabular}{|c|c|c|}
\hline & $\begin{array}{l}\text { b. Dependability } \\
\text { c. Confirmability } \\
\text { d. Transferability } \\
\text { C. Audit Trail Notes } \\
\text { a. Structure of Trail }\end{array}$ & \\
\hline $\begin{array}{l}\text { Intentions and } \\
\text { Disposition }\end{array}$ & $\begin{array}{l}\text { A. Proposal } \\
\text { a. Goals, Objectives, and Inquiry Questions } \\
\text { b. Relevant Literature } \\
\text { c. Theoretical Foundation } \\
\text { B. Reflexive Journaling } \\
\text { C. Expectations } \\
\text { a. Predictions } \\
\text { b. Intentions }\end{array}$ & $\begin{array}{l}\text { A. Refer to Chapter } 1 \\
\text { B. Peer Debriefing Interactions } \\
\text { C. Member Checks } \\
\text { a. Initial } \\
\text { b. Final } \\
\text { D. Researcher Triangulation } \\
\text { E. Reflexive Journals } \\
\text { a. Researcher } 1 \\
\text { b. Researcher } 2\end{array}$ \\
\hline $\begin{array}{l}\text { Instrument } \\
\text { Development }\end{array}$ & A. Preliminary Schedules of Questions & $\begin{array}{l}\text { A. Interview } \\
\text { B. Flier } \\
\text { C. PHMH Consent } \\
\text { D. Researcher's Confidentiality Agreement } \\
\quad \text { a. Researcher } 1 \\
\quad \text { b. Researcher } 2 \\
\text { E. Informed Consent } \\
\text { F. IRB Approval }\end{array}$ \\
\hline
\end{tabular}


Appendix H

Data Analysis 


\section{Data Analysis}

\section{Codes to Categories}

\begin{tabular}{|c|c|}
\hline Category & Corresponding Codes \\
\hline Emotional Expression & $\begin{array}{c}\text { Anger } \times 10 \text {, shame/embarrassment } \times 4 \text {, } \\
\text { revenge } \times 2 \text {, fear } \times 4 \text {, "I don't care" attitude } \times 4 \text {, } \\
\text { compassion } \times 2 \text {, numbness } \times 2 \text {, overwhelming } \\
\times 2 \text {, emotional strength } \times 2 \text {, emotions, } \\
\text { perseverance, hospitable, emotional wreck, } \\
\text { physical and emotional pain, happy then } \\
\text { crash, loss of control, "waking up" x } 2, \\
\text { defensiveness, denial, guarded, being } \\
\text { accepted is challenging, confusion, concerned } \\
\text { about behaviors, snappy, inconsiderate, hyper, } \\
\text { defeated, happiness, misunderstood, guilt, } \\
\text { grieving. }\end{array}$ \\
\hline Symptoms of Ml & $\begin{array}{l}\text { Slower moving } \times 4 \text {, manage pain } \times 2 \text {, } \\
\text { comorbidities } \times 4 \text {, memory problems } \times 5 \text {, high } \\
\text { functioning } \times 2 \text {, voices } \times 10 \text {, sleep issues } \times 3 \text {, } \\
\text { physical injury } \times 3 \text {, short fuse syndrome } \times 3 \text {, } \\
\text { telepathy } \times 2 \text {, suicide } \times 3 \text {, mood stability } \times 3 \text {, } \\
\text { obsessions, god wanted me to suffer Ml, } \\
\text { awareness of deficits, fighting Ml, concerns } \\
\text { about death, hearing problems. }\end{array}$ \\
\hline Previous life experiences & $\begin{array}{l}\text { Marriage } \times 3 \text {, abuse } \times 10 \text {, maturity } \times 5 \text {, building } \\
\text { character } \times 2 \text {, "I grew up but was never a kid" } \\
\times 2 \text {, state hospital } \times 2 \text {, moving } \times 2 \text {, lack of } \\
\text { memory, loss of friendship prior to diagnosis, " } \\
\text { actual" person, nightmares when first } \\
\text { diagnosed, hell, eye-opening moments, lowest } \\
\text { point, growing up in a single parent household, } \\
\text { past experiences of failure, experiences lead } \\
\text { to being loving and compassionate person, no } \\
\text { norm for growing up, accident changed } \\
\text { perspective, attitude has changed the most in } \\
\text { life, why try statements don't bug me anymore, } \\
\text { "maturity, heartache, and bad shit lead me to } \\
\text { change my mind of thoughts, loss of a child x } \\
2 \text {, poor past relationships, } 1 \text { life changing } \\
\text { moment, settled as a result of MI, what's done } \\
\text { is done, death of a family member, painful } \\
\text { childhood, more respect from where I grow up, } \\
\text { run away/things were awful. }\end{array}$ \\
\hline Societal Impact & $\begin{array}{l}\text { Bad rep for all with } \mathrm{Ml} \times 3 \text {, ashamed of } \\
\text { situation } \times 3 \text {, feelings of inequality } \times 3 \text {, } \\
\text { explaining situation } \times 4 \text {, I wish more people } \\
\text { were educated on } \mathrm{Ml} \times 2 \text {, influence of location }\end{array}$ \\
\hline
\end{tabular}




\begin{tabular}{|c|c|}
\hline & $\begin{array}{l}\times 2 \text {, stupidity attributed to Ml } \times 3 \text {, treated } \\
\text { childish } \times 5 \text {, societal brands } \times 2 \text {, that guy's } \\
\text { crazy } \times 3 \text {, Ml is dangerous } \times 2 \text {, forgotten } \\
\text { accomplishments due to negative beliefs, } \\
\text { difficulty comprehending Ml stigma, "pulling } \\
\text { the pin," maladaptive coping, constant } \\
\text { criticism, "why try when everyone's laughing at } \\
\text { me," public transportation, "get a grip." }\end{array}$ \\
\hline Negative sense of self & $\begin{array}{l}\text { self-doubt } \times 7 \text {, no intelligence } \times 4 \text {, fear of } \\
\text { failure } \times 6 \text {, giving up due to why try statements } \\
\times 2, \text { I used to care what others thought } \times 2, \text { "I } \\
\text { can't do this," "nothing to celebrate" } \times 2 \text {, "awful } \\
\text { person" } x 2 \text {, "short end of the stick," people } \\
\text { think you're crazy, "woke up and realized I } \\
\text { don't have it as bad" - related to experiences } \\
\text { with why try statements, hit hard by diagnosis, } \\
\text { "not good enough to take a bullet for this } \\
\text { country" - referring to military won't want me, } \\
\text { previous feelings of "you won't date me } \\
\text { because I have Ml, changed opinion of } \\
\text { pessimism, "if you act weird, somebody's } \\
\text { going to make fun of you," no belonging, "envy } \\
\text { people who don't have Ml, insecure of } \\
\text { appearance, always felt "mentally unbalanced" } \\
\text { due to lack of self-trust, less fortunate than } \\
\text { others, believe I should be emotionally } \\
\text { stronger }\end{array}$ \\
\hline Future goals & $\begin{array}{l}\text { Wants to be healthier } \times 4 \text {, goal is to get a car } \times \\
3 \text {, goal is to increase social life } \times 2 \text {, tangible } \\
\text { life goals } \times 4 \text {, wants more money } \times 2 \text {, goal is to } \\
\text { be mentally stable } \times 3 \text {, goals prior to diagnosis } \\
\times 3 \text {, supporting oneself } \times 2 \text {, quit things upon } \\
\text { starting if difficult, supporting children is a goal, } \\
\text { "live the best I can," more goals now that I } \\
\text { have Ml, college degree, improve musical } \\
\text { abilities, goal to take care of self, previously } \\
\text { fear stopped from pursuing goals, goal is } \\
\text { longevity in employment, physical fitness } \\
\text { obsession, increased capability of achieving } \\
\text { goals compared to past. }\end{array}$ \\
\hline Coping with negative social encounters & $\begin{array}{l}\text { Look at you different } \times 3 \text {, difficulty trusting at } \\
\text { times } \times 4 \text {, becoming what you were told } \times 2 \text {, } \\
\text { don't disclose Ml } \times 4 \text {, frustration with pleasing } \\
\text { others } \times 2 \text {, picked on, others opinions don't } \\
\text { matter, receiving diagnosis confirmed negative } \\
\text { thoughts, mental illness diagnosis is a relief } x \\
2 \text {, approval of others, concerns with answering } \\
\text { right, lying to increase how others perceive } \\
\text { you, taken advantage of, being made fun of, } \\
\text { seeking inclusion, sharing too much, secrets }\end{array}$ \\
\hline
\end{tabular}




\begin{tabular}{|c|c|}
\hline & $\begin{array}{l}\text { from others, holding back } \times 2 \text {, constant } \\
\text { comparison to others } \times 2 \text {, negative social } \\
\text { experiences. }\end{array}$ \\
\hline Life views & $\begin{array}{l}\text { Time helps } \times 2 \text {, happiness is energy } \times 2 \text {, cruel } \\
\text { world } \times 2 \text {, lessons learned are positive } \times 2 \text {, a } \\
\text { life to live for } \times 2 \text {, overall life view was } \\
\text { pointless } \times 4 \text {, normalcy } \times 4, \text { I always try to feel } \\
\text { good } \times 3 \text {, no why try statements } \times 2 \text {, life is } \\
\text { precious, not worth the struggle, I question } \\
\text { how it'll all work out, better off alone than with } \\
\text { abusive relationships, no quitting, "I'd never } \\
\text { fall for stigma I know I'm independent," } \\
\text { envious of other's lifestyles but know I'm doing } \\
\text { the best I can, whatever happens happens, I } \\
\text { should have done more with my life, "I am } \\
\text { me." }\end{array}$ \\
\hline Governmental affiliations & $\begin{array}{l}\text { Comfort with assistance } \times 9 \text {, groups } \times 7 \text {, } \\
\text { working with a therapist } \times 2 \text {, poverty } \times 2 \text {, } \\
\text { incidence with the law } \times 4 \text {, caring society } \times 2 \text {, } \\
\text { no insurance to manage illness, difficulty } \\
\text { reaching for resources, "in the system," " } \\
\text { forgets" to seek healthcare services, bad credit }\end{array}$ \\
\hline Self-care & $\begin{array}{l}\text { Do the things you're expected to do } \times 2 \text {, } \\
\text { medication management } \times 9 \text {, increased self- } \\
\text { awareness } \times 2 \text {, increased assertiveness } \times 3 \text {, } \\
\text { increased caring for self } \times 3 \text {, independence, } \\
\text { dependent on others to care for self, managing } \\
\text { illness, chores in the home, keeping self busy, } \\
\text { makes sure things go right, likes routine, self- } \\
\text { control, content with life/no life goals prior to } \\
\text { diagnosis, home management affected by MI, } \\
\text { procrastination }\end{array}$ \\
\hline Substance abuse & $\begin{array}{l}\text { Drugs } \times 4 \text {, sobriety } \times 2 \text {, alcohol use } \times 13 \text {, } \\
\text { stress=thirst, dry drunk, functional drinker } \times 2 \text {, } \\
\text { coping with alcohol, AA attendance. }\end{array}$ \\
\hline Friend/relationship impacts & $\begin{array}{l}\text { Friends with Ml } \times 3 \text {, friend support } \times 2 \text {, minimal } \\
\text { friends } \times 4 \text {, gained friends with acceptance } \times \\
3 \text {, no interest in significant others } \times 2 \text {, } \\
\text { friendships are influential, coping with friends, } \\
\text { housemate issues, relationships diminished } \\
\text { due to diagnosis, troubled relationships, want } \\
\text { for female companionship - not relationship, } \\
\text { single life, good relationships with roommates, } \\
\text { a few friends don't reach full potential, many } \\
\text { friendships/acquaintances, got help after friend } \\
\text { expressed concern }\end{array}$ \\
\hline Family & $\begin{array}{l}\text { "You can't do it" statements from family } \times 4 \text {, } \\
\text { family history of } \mathrm{Ml} \times 3 \text {, unhealthy relationships } \\
\times 2 \text {, family is embarrassed, "family screamer," }\end{array}$ \\
\hline
\end{tabular}




\begin{tabular}{|c|c|}
\hline & $\begin{array}{l}\text { protective of family, close with family, } \\
\text { influences on family, family conflict, missing } \\
\text { family and friends, quality time with family, no } \\
\text { family now, never supported from family, } \\
\text { criticized from family, family in town, } \\
\text { decreased family interconnectedness, } \\
\text { discomfort in family situations. }\end{array}$ \\
\hline Hobbies/interests & $\begin{array}{l}\text { Hobbies, cars, writing books, guitar, bicyclist, } \\
\text { hot-rod magazines, in a band, disease } \\
\text { dictionary, cigarettes and cough drops, hunting } \\
\times 2 \text {, exercise } \times 2 \text {, reading } \times 3 \text {, continuing to } \\
\text { engage in meaningful activities } \times 2 \text {, music } \times 6\end{array}$ \\
\hline Life after diagnosis with MI & $\begin{array}{l}\text { Fear of success and failing } \times 2 \text {, figure myself } \\
\text { out first } \times 2 \text {, mending burned bridges, reviving } \\
\text { self-power/control, wants to feel more } \\
\text { challenged, getting on with life, working on } \\
\text { personal issues, continually improved } \\
\text { attitudes, overwhelmed by future, rebuilding } \\
\text { relationships, previously had feelings of } \\
\text { inferiority, learning to self-advocate, searching } \\
\text { for peace, taking control, respecting oneself, } \\
\text { looking forward, working on anger, not doing } \\
\text { awful things, working towards increasing trust, } \\
\text { age alterations in views } \times 4 \text {. }\end{array}$ \\
\hline Values & $\begin{array}{l}\text { Spirituality } \times 6 \text {, hard worker } \times 5 \text {, enjoys work } \times \\
2 \text {, money } \times 4 \text {, me time, teasing women, lover } \\
\text { for animals, going against core values }\end{array}$ \\
\hline Employment & $\begin{array}{l}\text { Employment } \times 5 \text {, discontentment with jobs } \times 3 \text {, } \\
\text { rapid cycling through jobs } \times 5 \text {, work made life } \\
\text { worth living, discomfort with coworkers due to } \\
\text { Ml, sustaining jobs, quit work after physical } \\
\text { injury }\end{array}$ \\
\hline Positive responses to $\mathrm{Ml}$ & $\begin{array}{l}\text { Viewing people with Ml as equal to others } \times 2 \text {, } \\
\text { fairly treated } \times 2 \text {, shift in types of friends since } \\
\text { MI, people have always treated me good, "a } \\
\text { lot of people with Ml you'd never know they } \\
\text { have it," no changes in how people treat you } \\
\text { since diagnosis, bettering yourself, } \\
\text { acceptance, "I am OK" } \times 2 \text {, earning respect, } \\
\text { perception of being better at things than } \\
\text { friends, not bothered by comments or looks, } \\
\text { not settling, no one's ever treated me badly. }\end{array}$ \\
\hline Acts of diminished sense of self & $\begin{array}{l}\text { Easy to give up } \times 2 \text {, mental breakdown } \times 2 \text {, } \\
\text { negative self-talk } \times 2 \text {, reflections of self, didn't } \\
\text { apply for the army due to Ml, self harm, I once } \\
\text { had an increased sense of self prior to taking } \\
\text { myself off meds, nagging doubt, why me?, } \\
\text { frightening daily activities initially, taking on } \\
\text { negative qualities, decreased self esteem, "I'm }\end{array}$ \\
\hline
\end{tabular}




\begin{tabular}{|c|c|}
\hline & not doing what l'm supposed to be doing." \\
\hline Education & $\begin{array}{l}\text { Attempted school } \times 2 \text {, GED } \times 2 \text {, dropped out } \times \\
2 \text {, college not for me } \times 2 \text {, attended college } \times 2 \text {, } \\
\text { school = depression, didn't go to class in } \\
\text { college, bipolar diagnosis got in the way of } \\
\text { school, avoided education, pursued college } \\
\text { degree, increased grades in school. }\end{array}$ \\
\hline Positive self-perceptions & $\begin{array}{l}\text { I'm not that bad off, mental illness has made } \\
\text { me emotionally tougher, good listener } \times 2 \text {, } \\
\text { confidence } \times 2 \text {, I always knew I was a good } \\
\text { guy, people person, better now than I was, } \\
\text { self-respect } x 2 \text {, I'm a good person due to not } \\
\text { upsetting anyone }\end{array}$ \\
\hline Self-isolation & $\begin{array}{l}\text { "I don't do a lot" } \times 5 \text {, need to protect self } \times 4 \text {, } \\
\text { comfort zone } \times 2 \text {, don't isolate }\end{array}$ \\
\hline Personal convictions & $\begin{array}{l}\text { Caring of others aspects in life, putting others } \\
\text { first, other responsibilities than self, feelings } \\
\text { responsible for others problems, increased } \\
\text { empathy due to Ml, provider, protecting others, } \\
\text { caregiver }\end{array}$ \\
\hline
\end{tabular}

\section{Categories}

\begin{tabular}{|l|l|}
\hline Categories & \# of Codes \\
\hline Emotional expression & 55 \\
\hline Symptoms of MI & 50 \\
\hline Previous life experiences & 49 \\
\hline Societal impact & 40 \\
\hline Negative sense of self & 40 \\
\hline Future goals & 34 \\
\hline Coping with negative social encounters & 33 \\
\hline Life views & 32 \\
\hline Governmental affiliations & 31 \\
\hline Self care & 30 \\
\hline Life after diagnosis with MI & 26 \\
\hline Friend/relationship impacts & 25 \\
\hline
\end{tabular}




\begin{tabular}{|l|l|}
\hline Family & 25 \\
\hline Substance abuse & 25 \\
\hline Hobbies/interests & 24 \\
\hline Values & 21 \\
\hline Employment & 17 \\
\hline Positive responses to MI & 16 \\
\hline Acts of diminished sense of self & 16 \\
\hline Education & 16 \\
\hline Positive sense of self & 13 \\
\hline Self isolation & 12 \\
\hline Personal convictions & 9 \\
\hline Total: 23 & Total: 639 \\
\hline
\end{tabular}

\section{Themes with Descriptors}

\begin{tabular}{|l|l|}
\hline Themes & Textural/Structural Descriptions \\
\hline Negative impact on self & $\begin{array}{l}\text { Initially receiving a mental health diagnosis influenced one's } \\
\text { sense of self negatively which influenced social relationships, } \\
\text { employment, and ability to cope adaptively without use of } \\
\text { substances. }\end{array}$ \\
\hline $\begin{array}{l}\text { Coping with negative } \\
\text { social encounters }\end{array}$ & $\begin{array}{l}\text { Learning to cope with negative social encounters in one's life } \\
\text { after diagnosis led to refinement or maintenance of future goals, } \\
\text { life views, and occupational participation. }\end{array}$ \\
\hline $\begin{array}{l}\text { Positive contributions to } \\
\text { one's sense of self }\end{array}$ & $\begin{array}{l}\text { Life experiences and support from mental health service } \\
\text { providers, family, and friends over time altered one's sense of } \\
\text { self positively and led to awareness of valued occupations. }\end{array}$ \\
\hline $\begin{array}{l}\text { Acceptance of diagnosis } \\
\text { and acknowledged need } \\
\text { for medication }\end{array}$ & $\begin{array}{l}\text { Acceptance of the diagnosis and acknowledgment of a need for } \\
\text { medication management to alleviate symptoms of their mental } \\
\text { illness improved one's occupational performance. }\end{array}$ \\
\hline
\end{tabular}




\begin{abstract}
Assertion
Self-stigma is experienced as changes in sense of self with the greatest impact shortly after the initial diagnosis of the mental illness; with time and external supports, the individual learns to accept and cope with the diagnosis, resulting in decreased self-stigma and increased occupational engagement.
\end{abstract}


Appendix I

Verification of Member Checking 


\section{Dear Participant,}

Our names are Alyssa and Taylor, and we would like to thank you for meeting with us recently and sharing your experiences about stigma. Your honesty in sharing is appreciated.

We have included a copy of the full transcripts for the interviews in which you participated. These transcripts are word-for-word from our meetings with you. We would like you to please take a few moments to read the transcript and make sure that all of the information is accurate. If you feel any of the information is incorrect, please make corrections on the document. You may also add any additional comments on the backside of this letter.

Please place the transcript in the envelope provided and seal it before returning to Mary by Monday, November 2.2015 at 4:00 pm. Mary will not read these transcripts, but she will return them to us. If you do not to return your transcript to Mary by November 2, 2015, we will assume that all of the information was correct and that you do not have any more thoughts to share.

We would like to thank you so much again for your participation. Your responses are a valued part of our study, and we greatly appreciate your sharing. The final results of our research study will be shared with you after everything is completed. If you have any questions, please contact Mary and she will help arrange a meeting with one of us. Sincerest thanks,

Alyssa \& Taylor 
Dear Participant,

Our names are Alyssa and Taylor, and we would like to thank you for meeting with us recently and sharing your experiences about stigma. Your honesty in sharing is appreciated.

We have included a copy of the results of our study. We developed the results based on your responses you shared during your interviews. We would like you to please take a few moments to look over the results of the study. If you have any additional comments, please feel free to write them on the backside of this paper

Please return your comments to Mary by Friday, December 11, 2015 at 4:00 pm. Mary will return your comments to us. If you do not to return comments to Mary by December 11, 2015, we will assume that you do not have any more thoughts to share.

We would like to thank you so much again for your participation. Your responses are a valued part of our study, and we greatly appreciate your sharing. If you have any questions, please contact Mary and she will help arrange a meeting with one of us.

Sincerest thanks,

Alyssa \& Taylor 